\title{
Concrete Confinement with Steel-Reinforced Grout Jackets
}

\author{
Georgia E. Thermou ${ }^{1 *}$, Konstantinos Katakalos ${ }^{1}$, George Manos $^{1}$ \\ ${ }^{1}$ Aristotle University of Thessaloniki, Dept. of Civil Engineering, 54124, Thessaloniki, Greece
}

\begin{abstract}
The potential of steel fiber reinforced jackets combined with inorganic matrix (cementitious grout matrix) as an alternative strengthening system to fiber-reinforced polymer (FRP) jackets was investigated experimentally in the current study. For this purpose, the novel jacketing device was applied on cylindrical specimens subjected to monotonic concentric uniaxial compression load. Parameters of investigation were the type of the steel fiber reinforced fabric, its density, the overlap length, and the concrete compressive strength. The $3 \mathrm{X} 2$ and $12 \mathrm{X}$ types of steel fabric were used with three alternative densities, characterized as high, medium and low density. Experimental evidence has shown that a single layer of SRG jacket has increased substantially both axial strength and deformation capacity. From the response of the SRG confined cylinders the degree of penetration of the grout matrix through the fabric as well as the overlap length are considered rather critical parameters for the effectiveness of the method. The experimental data were used for the derivation of a simple empirical confinement model which correlated well with other well-established FRP confinement models. The knowledge gained from this experimental study renders SRG jacketing a remarkably promising retrofit solution for reinforced concrete confinement.
\end{abstract}

Keywords: Axial Compression, Columns, Composites, Concrete, Confinement, Jacket, Mortar, Steel-Reinforced Grout Jackets, Steel Fabric

\section{Introduction}

A considerable part of the existing reinforced concrete $(\mathrm{R} / \mathrm{C})$ building stock in countries around the Mediterranean basin was built either without any seismic code provisions or with low level seismic demands. Therefore, the earthquake resistance of these buildings is in need of upgrading. This can be partly achieved through effective retrofitting that can incorporate means of increasing confinement of the $\mathrm{R} / \mathrm{C}$ cross-sections in order to enhance the compressive strength and inhibit non-ductile failure under compression. During recent decades this confinement can be easily achieved by utilizing fiber reinforced polymer (FRP) jacketing (carbon, glass or aramid) instead of traditional R/C jackets with steel transverse reinforcement. Fiber reinforced polymer (FRP) jacketing is considered one of the most efficient and widely used techniques in retrofitting $\mathrm{R} / \mathrm{C}$ members. It has the advantages of practically no change in the geometry of the $\mathrm{R} / \mathrm{C}$ member, it can be applied fast, and the FRP materials exhibit highstrength-to-weight ratio and corrosion resistance. One should also mention certain disadvantages that are related mainly to the high cost, toxicity and poor behavior at high temperatures when (FRP) jacketing (carbon, glass or aramid) are applied with epoxy resins. The potential of introducing new materials for such an external confinement of $\mathrm{R} / \mathrm{C}$ members that will minimise these disadvantages while keeping the advantages is a worthwhile research objective. This was partially

* Corresponding author, tel: 00302310995466, fax: 00302310995416, gthermou@ civil.auth.gr 
achieved by replacing the epoxy resins with grout matrix (e.g. FRM [1], TRM [2]). Furthermore, towards this direction, during the last decade, various types of steel reinforced fabrics were introduced as a new material for external confinement when combined with either polymer (steel reinforcing polymer SRP) or grout (steel reinforcing grout - SRG) [3]. This type of steel fabric consists of high strength steel cords embedded in epoxy resin or grout matrix. Most of the applications concern the use of SRP as externally bonded longitudinal reinforcement in flexural members [e.g. [3]-[13]] or as shear reinforcement [14]. The use of the steel reinforced fabric combined with cementitious grout as a jacketing device was investigated experimentally to predamaged cantilever specimens of old type detailing for the first time in 2007 by Thermou and Pantazopoulou [15]. Recently, El-Hasha and Mashrik [16], El-Hacha and Abdelrahman [17] investigated experimentally the confinement effectiveness of resin impregnated high density steel fiber reinforced fabric (SRP) jackets applied to both cylindrical and prismatic specimens.

The use of a cementitious matrix rather than epoxy represents a useful practical alternative for jacketing with improved fire resistance. Given the primary benefits observed and taking into account the greater familiarity that structural engineers have with steel, an experimental study was conducted in order to study the effectiveness of SRG jackets to increase the axial compressive capacity of concrete through confinement. A single layer of the SRG jacket was applied to unreinforced cylindrical specimens subjected to monotonic concentric uni-axial compression load with parameters of investigation the different type and densities of the steel fabrics, the overlap length and the concrete compressive strength.

The results have shown that a single layer of SRP jacket has increased substantially both strength and deformation capacity. The average strength increase ranged from $37 \%$ to $76 \%$, whereas the average axial strain increase ranged between $68 \%$ and $333 \%$. Two distinguished failure modes were observed depending on the overlap length. For the majority of the specimens with the short overlap length (equal to $120 \mathrm{~mm}$ ), debonding at termination of the steel fabric was observed. Tensile fracture of the grout impregnated fabric was the mode of failure in the case of the longer overlap length (equal to $360 \mathrm{~mm}$ ).

The steel-reinforced grout jacketing technique is an effective, simple and fast-in-application intervention method that can be applied to concrete columns for axial compressive strength and ductility enhancement. The use of the inorganic matrix combined with reduced density fabrics was highlighted in current research indicating the high potential of the proposed jacketing scheme. The key element for the success of the method was shown to be the good bond conditions between the steel fabric and the cementitious grout.

\section{Experimental program}

\subsection{Objective and parameters of this investigation}

The main objective of the experimental program was to investigate the efficiency and feasibility of steel fiber reinforced jackets combined with inorganic matrix (cementitious grout matrix) to increase the axial compressive capacity of concrete through confinement. For this purpose, a number of unreinforced cylindrical specimens with a diameter of $150 \mathrm{~mm}$ and a height of $300 \mathrm{~mm}$ were tested in uniaxial compression after the application of a single layer of steel fabric (Fig. 1). Previous research on FRP jacketing of unreinforced cylindrical specimens has 
shown that for slenderness ratios greater than 30 (height to diameter ratio, $H / D \approx 7.5)$ stability failure is anticipated, whereas the method is effective for slenderness ratios less than $40(H / D=10)$ [18-19]. In case of SRP jacketed cylinders the reduced efficiency of the method is observed for a slenderness ratio higher than $24(H / D=6)$ [17]. For the specimens tested herein, which have a slenderness ratio of $8(H / D=2)$, no stability problems are anticipated. The parameters considered in current experimental investigation are: (i) the type of the steel fabric, (ii) the density of the steel fabric, (iii) the overlap length and (iv) the concrete unconfined compressive strength.

Steel reinforced fabrics consist of unidirectional steel cords that are held in place by knit yarns forming an appropriate pattern of fabric (Fig. 1). Each cord is formed by twisting a number of steel filaments. The twisted steel filaments create a rough surface which provides a mechanical interlock with the matrix [20]. Two commercially available steel reinforced fabrics, the $3 \mathrm{X} 2$ and $12 \mathrm{X}$, with different mechanical properties, were used in the experimental program. The $12 \mathrm{X}$ wire cord is made by twisting two different individual wire diameters together in 12 strands with over twisting of one wire around the bundle (Figure 2(a)), whereas the $3 \mathrm{X} 2$ wire cord is made by twisting five individual wires together - three straight filaments wrapped by two filaments at a high twist angle (Figure 2(b)). The surface roughness provided by the $3 \mathrm{X} 2$ cord is considered more pronounced compared to that of the $12 \mathrm{X}$ cord [20]. The objective of using $12 \mathrm{X}$ and $3 \mathrm{X} 2$ steel fabrics was to investigate the influence of their mechanical properties on the behavior of the SRG jacketed cylindrical specimens.

The density of the fabric, which refers to the number and spacing of steel cords, is considered a rather crucial parameter for the success of the proposed jacketing system. The gap between cords controls the degree of penetration of the grout matrix through the fabric, as well as the effective area of the steel wire confinement. A high, medium and low density steel reinforced fabrics were utilized for the fabrication of the jackets, which correspond to $9.06 \mathrm{cords} / \mathrm{cm}$ (Fig. 2(c)), 2 cords/cm (Fig. 2(d)) and 1 cord/cm (Fig. 2(e)), respectively. The selection of this parameter aimed at investigating the influence of the tensile strength of the varying density fabrics on the provided lateral confining pressure.

The overlap length should be sufficient to avoid debonding from the end of the lap. For the case of cylindrical specimens wrapped with resin impregnated high density steel reinforced fabrics, El-Hacha and Mashrik [16] recommend an overlap length equal to $100 \mathrm{~mm}$. The present experimental investigation was carried out for two overlap lengths equal to $120 \mathrm{~mm}$ and $360 \mathrm{~mm}$, respectively. The short overlap length $(120 \mathrm{~mm})$ was selected based on the usual field practice recommendation for a square cross section ( $\mathrm{a} x \mathrm{a}$ ) jacketed with composite fabrics where the last jacket layer is lapped over one full side length (a) of the cross section for anchorage. This corresponds approximately to an equivalent length equal $133 \mathrm{~mm}$ for the case of the tested cylindrical specimen with the same crosssection. Based on this rationale and on similar tests carried out by other researchers (eg. [16]), the value of the short overlap length was chosen equal to $120 \mathrm{~mm}$. The long overlap length $(360 \mathrm{~mm})$ was taken three times that of the short overlap in an effort to meet the large bond strength demands of the high density steel fabric used for wrapping in one group of tested specimens. A partial objective of the variation of the overlap length was to explore its influence on the mode of failure. It would be desirable if one could deduce from the experimental results an overlap length that will provide sufficient anchorage of the fabric prohibiting the debonding mode of failure. 
The influence of the concrete unconfined compressive strength on the effectiveness of the SRG jackets was also explored. For this purpose, a low and a moderate concrete compressive strength were considered.

\subsection{Specimen details}

The cylindrical specimens are divided into two groups depending on the unconfined concrete compressive strength. Specimens of Group A were cast using concrete of a relatively low compressive strength classified as C12/15 [21], whereas Group B were cast using concrete of moderate compressive strength classified as C20/25 [21]. Four different types of specimens were constructed for each class of concrete compressive strength: the unconfined control specimens, specimens wrapped with the high density $(9.06$ cords/cm) steel fabric, specimens wrapped with the moderate density $(2$ cords $/ \mathrm{cm})$ steel fabric and specimens wrapped with the low density $(1 \mathrm{cord} / \mathrm{cm})$ fabric. The identification codes follow the notation QFDO_N, where Q stands for concrete class ("A" for C12/15 and "B" for C20/25), F denotes the type of the fabric (3X2 or 12X), D corresponds to the density of the fabric (" $h$ " for high density, " $m$ " for moderate density and " $\ell$ " for low density), $O$ the overlap length (" 1 " for the $360 \mathrm{~mm}$ and " 2 " for the 120 $\mathrm{mm}$ overlap length) and $\mathrm{N}$ refers to the specimen number for each subgroup of

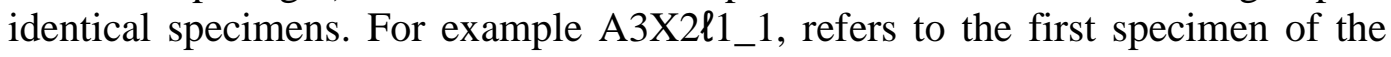
subgroup of specimens of concrete compressive strength $\mathrm{C} 12 / 15$ that are wrapped with a low density $(1 \mathrm{cord} / \mathrm{cm}) 3 \mathrm{X} 2$ steel reinforced fabric and have an overlap length equal to $360 \mathrm{~mm}$. All types of specimens are summarized in the second

column in Tables $1 \mathrm{a}$ and $1 \mathrm{~b}$. Three samples were constructed from each type of specimens with the exception of the high density fabric jacketed specimens (A3X2h1, A12Xh1) where only two samples of each type were constructed. The total number of the specimens tested was 34 .

\subsection{Material properties}

The specimens were cast in two batches corresponding to the two qualities of concrete compressive strength. Ordinary Portland Cement was used with a water:cement:sand:gravel proportion equal to $0.7: 1: 2.7: 3.3$ for $\mathrm{C} 12 / 15$ and 0.55:1:1.9:2.3 for $\mathrm{C} 20 / 25$.

The two types of high carbon steel cords, $3 \mathrm{X} 2$ and $12 \mathrm{X}$, utilized in the experimental program had a micro-fine brass coating also known as AOBrass (adhesion optimizer) which enhances the corrosion resistance [e.g. 10, 12, 16]. The tape density of the original $3 \mathrm{X} 2$ and $12 \mathrm{X}$ steel reinforced fabrics, as produced by the manufacturer, was 9.06 cords/cm considered high-density tape (Fig. 2(c)). The modified density of both the 3X2 and 12X consisted of 2 cords/cm (Fig. 2(d)) and $1 \mathrm{cord} / \mathrm{cm}$ (Fig. 2(e)) characterized herein as medium and low density, respectively. Redundant cords were removed manually, paying attention not to damage the underlying net that essentially keeps the cords in position. The distance of 1.0 and $0.5 \mathrm{~cm}$ between successive cords in the low and medium density was considered satisfactory for uninhibited flow of the cementitious grout through the steel reinforced fabric. The geometrical and mechanical properties of a single cord as provided by the manufacturer are presented in Table 2.

A small number of tensile tests were carried out according to ASTM D3039 [22] in order to verify the mechanical properties of the steel cords. Two types of coupons were fabricated, which are differentiated as per the type of the fabric (i.e. 12X and 3X2) and having a density of 9.06 cords/cm (high density). Three identical coupons of each type were constructed. The results are presented 
in Table 3 and the average stress-strain curves appear in Fig. 3. In order to make feasible the comparison between the steel and other composite fabrics, an equivalent thickness per unit width, $t_{s}$, was defined for the steel fabrics with varying density. The axial stiffness, $K_{f, s}=t_{s} \cdot E_{f, s}$, as well as the tensile strength, $f_{f u, s}$, of the various steel fabrics appear in Table 4. For example, the axial stiffness of a thin carbon fabric equal to $25300 \mathrm{~N} / \mathrm{mm}(=0.11 \cdot 230000$, where $0.11 \mathrm{~mm}$ is the thickness of the fabric and $230000 \mathrm{MPa}$ the modulus of elasticity) corresponds to $35 \%$ of the axial stiffness of the high density fabric (Fig. 2(c)), whereas it is 1.6 and 3.1 times higher compared to the axial stiffness of the medium (Fig. 2(d)) and low (Fig. 2(e)) density steel fabrics, respectively.

A commercial cementitious grout with fibers and special additives was utilized as a binding material for the application of the SRP jackets. The mechanical characteristics at 28 days according to the manufacturer are flexural strength $6.78 \mathrm{MPa}$, compressive strength $22.1 \mathrm{MPa}$, adhesion to dry concrete 1.88 $\mathrm{MPa}$ and modulus of elasticity $8.03 \mathrm{GPa}$.

\subsection{Test setup and data collection}

The cylindrical specimens were subjected to monotonically increasing concentric uniaxial compression load up to failure. The loading was applied at a rate 0.15 $\mathrm{MPa} / \mathrm{sec}$ in load control, using a $2000 \mathrm{kN}$ compression testing machine. Axial strain was measured as the average of four linear variable differential transducers (LVDTs) mounted on the four corners of the top stiff metallic square slab placed between the load cell and the concrete specimen (Fig. 4). Axial load was measured from a load cell placed at the top of the specimen (Fig. 4). The lateral strains are very crucial for the assessment of the efficiency of the novel technique; however, due to experimental constrains, it was not possible to provide accurate and reliable measurements of this parameter in the current testing sequence.

\subsection{Fabrication of SRG jackets}

After removing the moulds (after 80 and 52 days for the specimens of Group A (C12/15) and Group B (C20/25), respectively) the substrate of the unconfined specimens was saturated with water before proceeding to the application of the cementitious grout (Fig. 5(a)). The cementitious grout was applied manually with the help of a trowel directly onto the lateral surface of the cylinder (Fig. 5(b)). The metallic fabric was placed immediately after the application of the cementitious grout (Fig. 5(c)). The grout was squeezed out between the steel fibers by applying pressure manually (Fig. 5(d)). After the application of the fabric to one full-cycle the remaining length was lapped over the lateral surface (Fig. 5(e)). A final coat of the cementitious grout was applied to the exposed surface (Fig. 5(f)). The effect on the geometric dimensions of the jacketed specimens was small. The grout layer including the steel reinforced jackets was $7 \mathrm{~mm}$ thick, so that the final diameter of the cylindrical specimens was $164 \mathrm{~mm}$, with an exception regarding the high density fabric jackets (A3X2h, A12Xh, Table 1a) where the thickness of the composite system was $10 \mathrm{~mm}$. The thickness of the grout layer was such as to guarantee that the steel fabric was fully embedded in the cementitious matrix.

The SRG jackets were fabricated as to fit the height of the specimen. In case of the high density jackets the steel fabric was cut precisely to fit the height of the specimen, whereas in the reduced density fabrics, a small gap was left unintentionally, of the order of $1 \mathrm{~mm}$, due to the structure of the fabric (gap between cords). Therefore, this "gap" was not a parameter of the current investigation. The self-leveling high-strength mortar, placed at the top and bottom 
surface of the cylinders in order to ensure smooth surface for uniform loading created an insignificant gap $(<1 \mathrm{~mm})$.

\section{Test results and discussion}

\subsection{Axial stress-strain responses}

\section{Specimens of Group A:}

The stress-strain diagrams of the SRG jacketed cylindrical specimens of Group A (concrete compressive strength $\mathrm{C} 12 / 15$, overlap length $360 \mathrm{~mm}$ ) for all the density types of jackets are depicted in Fig. 6, along with the average stress-strain curve of the control specimens (curve "A"). As observed the response is differentiated depending on the type (12X or $3 \times 2$ ) and the density (low, medium, high) of the steel fiber reinforced fabric. The typical stress-strain curve is characterized as trilinear. The first part comprises an ascending branch having the same inclination with that of unconfined concrete. The second part is nearly linear with or without inclination (positive or negative), whereas the third one corresponds to a descending branch with constant slope denoting failure of the jacket. The stressstrain curve of the $12 \mathrm{X}$ high density steel fabric (Fig. 6(c)) is differentiated and is characterized as a bilinear curve with an ascending and descending branch with constant slope.

Test results for each specimen which refer to the concrete compressive strength, $f_{c c}{ }^{\prime}$, and the corresponding strain, $\varepsilon_{c c}$, as well as to the ultimate compressive strength, $f_{c c, u}$, and the corresponding strain, $\varepsilon_{c c u}$, along with the mean and standard deviation are presented in Tables 1a and $1 \mathrm{~b}$ for Group A and Group $\mathrm{B}$, respectively. The ultimate compressive strength, $f_{c c, u}$, corresponds to $20 \%$ drop in compressive strength $f_{c c}{ }^{\prime}$ (i.e. $0.80 f_{c c}{ }^{\prime}$ ). The effectiveness of the proposed jacketing system is assessed in terms of the concrete compressive strength, $f_{c c}{ }^{\prime}$, and the ultimate strain, $\varepsilon_{c c u}$, reached. In general, the response of the SRG jacketed specimens improved substantially both strength and deformability. The gain in compressive strength ranged between $47 \%$ and $76 \%$, whereas the gain in ultimate strain ranged between $148 \%$ and $333 \%$ (The increase in compressive strength and ultimate strain are defined as $\left(f_{c c}{ }^{\prime}-f_{c o}\right) / f_{c o}{ }^{\prime}$ and $\left(\varepsilon_{c c u}-\varepsilon_{c o}\right) / \varepsilon_{c o}$, respectively, with $\varepsilon_{c o}=2 \%$. The mean values of $f_{c c}{ }^{\prime}$ and $\varepsilon_{c c u}$ are used). In case of the high density steel fabric $(9.06 \mathrm{cords} / \mathrm{cm}$, Fig. 2(c)), the concrete compressive strength increased by $47 \%$ and $67 \%$ for $3 X 2$ and $12 X$, respectively. The same levels of strength increase were observed for the low density SRG jackets (51\% and $49 \%$ for $3 \mathrm{X} 2$ and $12 \mathrm{X}$, respectively). The gain in compressive strength was a bit higher for the medium density fabrics (70\% and $76 \%$ for the $3 \mathrm{X} 2$ and $12 \mathrm{X}$, respectively). Despite the fact that the lateral stress provided by the high density fabric is nine times higher compared to that provided by the low density fabric, this is not reflected in the concrete compressive strength increase due to the type of failure mode which occurred. It is reminded that the overlap length for all the specimens in Group A was $360 \mathrm{~mm}$. The low density SRG jackets failed due to rupture of cords whereas the high density SRG jackets due to debonding from the end of the lap. In the first case, the fabric exhausted its capacity, whereas in the second case the weak link was the shear strength of the cementitious mortar at the interface between the steel fabric and the grout. As far as the medium density fabrics are concerned, half specimens failed due to debonding whereas the rest due to rupture of the fabric (see Table 1a). 
The comparison of the average response curves of Group A provides a clear insight into the behavior of the various jacketing systems (Fig. 7). It seems that the most efficient use of the fabric takes place in the case of the low density fabrics for both $12 \mathrm{X}$ and $3 \mathrm{X} 2$ types and overlap length equal to $360 \mathrm{~mm}$ (A3X2 $\ell 1$ and A12X 1 see Table 1a) despite the fact that both strength and strain gain was lower compared to the medium density fabrics. This is justified by considering that the steel fabric exhausted its own strength in all cases (i.e. rupture of the fabric). The influence of the higher tensile strength of the $3 \times 2$ fabric compared to the 12X fabric (Fig. 3), estimated equal to $17 \%$ (Table 3), is investigated. As it can be seen in Table 1a the specimens with the $3 \mathrm{X} 2$ fabric have an average compressive strength equal to $f_{c c}{ }^{\prime}=22.80 \mathrm{MPa}$ as compared to a value of $f_{c c}{ }^{\prime}=22.55$ $\mathrm{MPa}$ for the specimens with the $12 \mathrm{X}$ fabric. Thus, the specimens with the $17 \%$ stronger fabric $(3 \times 2)$ exhibit only an insignificant $1.1 \%$ increase in their compressive strength when compared to the specimens with the relatively weaker fabric (12X). However, excluding from the averaging process specimen A12X 1 1_3, due to its unaccountable higher compressive strength than its counterparts, the average value of $21.45 \mathrm{MPa}$ is found for the specimens with the $12 \mathrm{X}$ fabric. This time, the specimens with the $17 \%$ stronger fabric $(3 \times 2)$ exhibit a $6.3 \%$ increase in their compressive strength when compared to the specimens with the relatively weaker fabric $(12 \mathrm{X})$. Thus, it can be concluded that a relatively small portion of the increase in the strength of the fabrics (at best 1/3) is utilized by the jackets in the examined specimens. For the same subgroup of specimens, an index that has been used by many researchers to describe the confinement effectiveness of the FRP jacketed columns, the Modified Confinement Ratio (MCR) [23], is evaluated. In case of cylindrical specimens the confinement ratio is defined as the ratio $\sigma_{l a t} / f_{c o}{ }^{\prime}$, where $\sigma_{\text {lat }}$ is the lateral confining pressure exerted by FRP jackets and $f_{c o}{ }^{\prime}$ is the compressive strength of unconfined concrete. Spoelstra and Monti [24] proposed a minimum value of $\sigma_{\text {lat }} / f_{c o}=0.07$ for sufficient confinement. This limit value was also adopted by Teng et al. [25]. In case of the SRG jacketed cylinders and considering those wrapped with the low density fabrics (i.e. $1 \mathrm{cord} / \mathrm{cm}$ ) and an overlap length equal to $360 \mathrm{~mm}$ the calculated confinement ratios are for the $12 \mathrm{X}$-type of fabric equal to $\sigma_{\text {lat }} / f_{c o}{ }^{\prime}=0.10$, whereas for the 3X2-type of fabric equal to $\sigma_{\text {lat }} f_{c o}{ }^{\prime}=0.11$.

\section{Specimens of Group B:}

The response of specimens of Group B (concrete class C20/25, overlap length 120 $\mathrm{mm}$ ) is slightly differentiated compared to that of specimens of Group A (concrete class C12/15, overlap length $360 \mathrm{~mm}$ ). It is noted that in this group of specimens, fabrics of low and medium density only were used. The stress-strain curves in the majority of the cases can be characterized as bilinear with an ascending branch having the same inclination with that for unconfined concrete and a descending branch of constant slope (Fig. 8). They resemble second order polynomial curves. In some cases and only for the medium density fabric, a plateau is observed at the peak stress.

Regarding the efficiency of the SRG jacketing system with an overlap length $120 \mathrm{~mm}$, the gain in compressive strength ranged between $37 \%$ and 54\%, whereas the gain in ultimate strain ranged between $68 \%$ and $167 \%$. If these results are compared with the corresponding ones of Group A (one layer of SRG jacket for low and medium density fabrics with an overlap length equal to $360 \mathrm{~mm}$ ), it is concluded that the effectiveness of SRG jackets increases as the unconfined concrete strength decreases. This conclusion is in accordance to similar 
observations made in case of FRP jacketing [26, 27] as well as Textile Reinforced Mortar (TRM) jacketing [2].

The comparison of the average response curves for the SRG jacketed specimens with an overlap length equal to $120 \mathrm{~mm}$ is depicted in Fig. 9. For this group of specimens, no solid conclusions can be drawn for the efficiency of the SRG jackets since most of the specimens even those with the low density fabrics failed in debonding due to inadequate overlap length (see Table 1b).

From the above, it is seen that the effectiveness of the proposed singlelayered jacketing system seems to be a balance between the axial stiffness of the fabric, the degree of penetration of the grout matrix through the fabric and the overlap length. This implies that the high strength is not a necessary demand for the steel fabrics. It should be stated that these observations are limited to singlelayered SRG jackets with the specific grout characteristics utilized herein. Extension of the conclusions to multiple layer SRG jackets requires further experimental investigation that will be dealt with in the future.

\subsection{Modes of failure}

Steel reinforced grout (SRG) jackets provide confinement as external reinforcement. SRG jackets exert a continuously increasing confining action up to

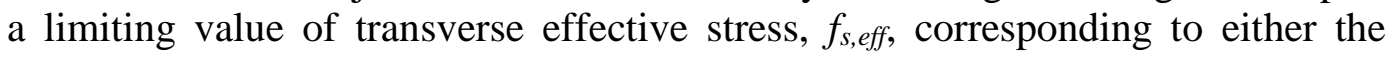
transverse stress reached at rupture of the steel reinforced fabric, $f_{s, \text { rupt }}$, or the transverse stress at debonding failure of the jacket layer, $f_{s, d e b}$, over the lap length, $L_{b}$ :

$$
f_{s, e f f}=\min \left(f_{s, d e b} ; f_{s, r u p t}\right)
$$

The value of $f_{s, d e b}$ is determined by the strength of the bonded system which in turn relies on the shear stress-strain response of the grout which may be assumed elastic with brittle rupture as shown in Fig. 10, with $f_{g, u}$ the rupture shear strength and $s_{g, u}$ the slip value at shear failure $[28,29]$. The grout, which is considered the weak link of the composite system, is stressed in shear along the overlap length, $L_{b}$. The value of $f_{s, d e b}$ is influenced by both the characteristics of the grout (interfacial bond stress) as well as the thickness of the fabric. The knowledge of the limiting value of the transverse effective stress, $f_{s, \text { eff }}$, is crucial for estimating the required effective confining pressure, $\sigma_{l a t}$, and thus the required number of fabric layers (i.e jacket thickness).

From the tests carried out and the parameters studied, the density of the fabric and the overlap length affected mostly the effectiveness of the SRG jacketed cylinders. In case of the long overlap length (equal to $360 \mathrm{~mm}$, Group A specimens, Table 1a) the high density SRG jacketed cylinders failed due to debonding whereas the low and medium density SRG jacketed cylinders failed in their majority (nine out of twelve, Table 1a) due to tensile fracture of the steel cords. Most of the specimens that failed due to debonding presented a characteristic vertical crack at termination of the steel fabric (Fig. 11(a), (e), (g)). The high density fabrics due to the very small distances between successive cords (only $1.1 \mathrm{~mm}$ ) did not allow the cementitious grout to penetrate through the gaps between successive cords. Therefore, the development of an interlocking mechanism between the steel cords and the cementitious matrix was unfeasible. The only bond mechanism developed in this case is attributed to the shear strength of the mortar and the surface roughness of the steel fabric. As a result, the high value of the axial stiffness / strength of the high density fabric could not be 
balanced by the shear strength of the mortar, thus leading to debonding. Considering the effect of the short overlap length (equal to $120 \mathrm{~mm}$, Group B specimens, Table 1b) most of the low and medium density SRG jackets failed due to debonding. Hence, it was pointless to test high density SRG jackets with such an overlap length.

For the low and medium density fabrics, penetration of the mortar through the spacing of the steel cords enhanced the developed bond between the fabric and the matrix. The overlap length played a decisive role on the mode of failure observed. The long overlap length $(360 \mathrm{~mm})$ led to tensile fracture of the steel cords (Group A specimens, Table 1a), whereas the short overlap length (120 mm) to debonding (Group B specimens, Table 1b). In case of tensile fracture, failure occurred gradually since the fracture of the individual steel cords was progressive, a fact that is noticeable by the slope of the third part of the tri-linear response curves (Fig. 6). Rupture of the steel cords initiated close to the termination of the steel fabric. Representative specimens that failed due to tensile fracture of the steel cords are depicted in Fig. 12.

In light of the above, it can be stated that the short overlap length equal to $120 \mathrm{~mm}$ is insufficient to provide anchorage to the low and medium density fabrics. As far as the long overlap length equal to $360 \mathrm{~mm}$ is concerned, it may be considered sufficient for anchorage of the low density SRG jacketed cylindrical specimens and insufficient for the medium density SRG jacketed cylindrical specimens. Moreover, the high density SRG jackets, due to the difficulty of being penetrated by the cementitious material, will lead to debonding failure easily, thus rendering their application of less practical interest than that of the low or medium density SRG jackets.

\section{Analytical study}

The results of the SRG jacketed cylinders were utilized for the derivation of a simple empirical confinement model which relates the confined strength and ultimate strain and their unconfined counterparts. Analytical and empirical confinement models derived for fiber-reinforced polymer (FRP) jacketed cylinders as well as steel confinement models were used for comparison.

\subsection{Lateral confining pressure}

In the analytical study carried out herein, two approaches were followed for estimating the lateral confinement, $\sigma_{\text {lat }}$, provided by the SRG jackets (Fig. 13(a)).

(i) First approach - Steel fabric with equivalent thickness per unit width:

In the first approach, an equivalent thickness per unit width was defined for the steel fabric (Table 4). The lateral confining pressure provided by the steel fabric of equivalent thickness $t_{s}$ with cords circumferentially aligned and covering the total concrete surface is given by [30]:

$\sigma_{\text {lat }, f}=\frac{1}{2} K_{e f f} \cdot \rho_{S R G} \cdot f_{s, e f f}$

where $\rho_{S R G}$ is the volumetric ratio of the SRG jacket, $f_{s, e f f}$ is the transverse effective stress of the steel reinforced fabric and $K_{\text {eff }}$ is the effectiveness coefficient calculated by considering that the transverse pressure from the confining scheme is only effective where the confining pressure has fully developed due to arching action. The effectiveness coefficient $K_{\text {eff }}$ was taken equal 
to unit for all the fabric densities examined herein, despite the fact that the finite gaps between cords in case of the medium and low density fabrics influence the effectiveness of confinement along the height of the specimen (Fig. 13b). The steel fabric was intentionally considered as a continuous fabric along the height of the specimen having the estimated equivalent thickness. The volumetric ratio of the SRG jacket is defined according to:

$\rho_{S R G}=\frac{4 \cdot t_{s}}{D}$

where $t_{s}$ is the equivalent thickness per width of the steel fabric and $D(=150 \mathrm{~mm})$ is the diameter of the cylindrical specimen. The lateral confining pressure may be further simplified after substitution of Eq. (3) into Eq. (2) to:

$$
\sigma_{\text {lat }, f}=2 \frac{t_{s}}{D} f_{s, e f f}
$$

where $t_{s}$ is the equivalent thickness per width of the steel fabric, $D(=150 \mathrm{~mm})$ is the diameter of the cylindrical specimen and $f_{s, e f f}$ is the transverse effective stress of the steel reinforced fabric.

(ii) Second approach - Steel cords are treated as steel stirrups placed at distances equal to the distances between cords.

In the second approach, the steel cords were treated as well-anchored steel stirrups placed at a distance equal to the spacing between the steel cords. In this case, it was considered that partial wrapping is provided along the height of the specimen (Fig. 13(b)). The lateral confining pressure provided by the steel cords circumferentially aligned is given by:

$$
\sigma_{\text {lat }, s}=\frac{1}{2} K_{e f f} \cdot \rho_{S R G} \cdot f_{s, e f f}
$$

where $\rho_{S R G}$ is the volumetric ratio of the SRG jacket, $f_{s, e f f}$ is the transverse effective stress of the steel cords and $K_{\text {eff }}$ is the effectiveness coefficient. In case of the high density steel fabric, the cylindrical specimens are considered fully wrapped, thus the effectiveness coefficient, $K_{\text {eff, }}$ is equal to unit. When steel reinforced fabrics of reduced density are considered, then partial wrapping is provided. The retrofit scheme in this case is less efficient since both confined and unconfined zones exist (Fig. 13(b)). The effectiveness coefficient may be calculated as:

$$
K_{e f f}=\left(1-\frac{s^{\prime}}{2 D}\right)^{2}
$$

where $s^{\prime}\left(=s-D_{c}\right)$ is the clear spacing between the steel cords, $D_{c}$ is the diameter of the steel cord (Table 2) and $D(=150 \mathrm{~mm}$ ) is the diameter of the cylindrical specimen. Eq. (6) is used also to express the effectiveness in case of partially wrapped FRP-jacketed members [30]. The estimated values of $K_{\text {eff }}$ for the 5 and $10 \mathrm{~mm}$ gap between successive steel cords are equal to 0.97 and 0.94, respectively. This implies that there is practically no effect on the lateral confining pressure exerted by steel cords placed at such small distances. The authors believe 
that further investigation is required in order to examine whether the behavior of steel cords resembles that of closed stirrups for even larger distances between the steel wires. The volumetric ratio of the SRG jacket is defined according to:

$\rho_{S R G}=\frac{\pi \cdot D_{c}^{2}}{s \cdot D}$

where $D_{c}$ is the diameter of the steel cord (Table $\left.2, D_{c}=0.889 \mathrm{~mm}\right), D(=150 \mathrm{~mm}$ ) is the diameter of the cylindrical specimen and $s$ is the distance between successive cords. After some algebraic manipulation of the above expressions the lateral confining pressure exerted by SRG jackets with steel cords at a distance, $s$, is:

$\sigma_{\text {lat }, s}=0.39\left(2 D-s^{\prime}\right)^{2} \frac{D_{c}^{2}}{s \cdot D^{3}} f_{s, e f f}$

In the cases where the estimated effectiveness coefficient, $K_{\text {eff, }}$ is close to unit, then the lateral confining pressure may be simplified to:

$\sigma_{\text {lat }, s}=1.57 \frac{D_{c}^{2}}{s \cdot D} f_{s, e f f}$

In Fig. 14(a) the distance between cords is plotted against the provided lateral confining pressure for the $3 \mathrm{X} 2$ and the $12 \mathrm{X}$ fabric for cylindrical specimens of $D=150 \mathrm{~mm}$ according to Eq. (8). It is observed that the lateral confining pressure when the distance between cords is $5 \mathrm{~mm}$ and $10 \mathrm{~mm}$ is reduced to almost five and ten times, respectively.

The objective behind using these two alternative approaches was to see at what extent the lateral confining pressure estimates are influenced by ignoring the effectiveness coefficient in the equivalent thickness per unit width approach. The comparison of the lateral confining pressure estimated by Eq. (4) and by Eq. (8) corresponding to the equivalent thickness per unit length and steel stirrup approach, respectively, reveals that the two approaches are equivalent. For example, in case of the $3 \mathrm{X} 2$ fabric with varying density the comparison is depicted in Fig. 14(b). It is obvious that due to the minor influence of the effectiveness coefficient $K_{\text {eff }}$ (it is remembered that for the low and medium density fabrics it was almost equal to unit) the two approaches gave the same results. The authors decided to follow the steel stirrup approach (i.e. steel cords are treated as steel stirrups placed at distances equal to the distance between cords) since it is in their future plans to investigate the influence of the spacing between steel cords on the exerted lateral confining pressure.

\subsection{Proposed empirical confinement model}

The most common form of concrete confinement models relates the confined strength $f_{c c}{ }^{\prime}$ and ultimate strain $\varepsilon_{c c u}$ to the confining stress at failure, $\sigma_{l a t}$, through the following set of equations:

$\frac{f_{c c}^{\prime}}{f_{c o}^{\prime}}=1+\kappa \cdot\left(\frac{\sigma_{l a t}}{f_{c o}^{\prime}}\right)^{a}$ 


$$
\varepsilon_{c c u}=\varepsilon_{c o}+\lambda \cdot\left(\frac{\sigma_{l a t}}{f_{c o}^{\prime}}\right)^{\beta}
$$

where $f_{c o}{ }^{\prime}$ is the compressive strength of the unconfined concrete, $\varepsilon_{c o}$ is the strain at failure of unconfined concrete, $\sigma_{\text {lat }}$ is the lateral stress due to jacketing and $\alpha, \beta$ $\kappa, \lambda$ are empirical constants. There are confinement models where $\alpha, \beta$ are taken equal to unity, thus $f_{c c}{ }^{\prime}$ and $\varepsilon_{c c u}$ are in linear proportion to $\sigma_{l a t}$, and others where nonlinearity is introduced by considering values of $\alpha, \beta$ in the majority of the cases less than 1 (see Table 5).

The findings of current experimental program were utilized for the derivation of an empirical model for SRG jacketed columns. In order to avoid any further complexity since our objective was not to elaborate on confinement models for concrete, coefficients $\alpha, \beta$ were taken equal to 1 . The experimental data of the confined cylinders with the low and medium density fabric that failed due to fracture of the steel reinforced fabric were utilized for the determination of $\kappa, \lambda$ (Eqs. (10)) by best fit linear equations which appear in Fig. 15. Each point in the graph of Fig. 15 corresponds to the average value of the specimens with the same characteristics that failed due to rupture. A total number of twelve specimens are considered (see Tables $1 \mathrm{a}$ and $1 \mathrm{~b}$ ). The values defined for $\kappa, \lambda$ were $\kappa=3.7, \lambda=27$. Hence, the following expressions result:

$$
\begin{aligned}
& \frac{f_{c c}^{\prime}}{f_{c o}^{\prime}}=1+3.7 \frac{\sigma_{l a t}}{f_{c o}^{\prime}} ;\left(R^{2}=0.69\right) \\
& \varepsilon_{c c u}=2+27 \cdot \frac{\sigma_{l a t}}{f_{c o}^{\prime}} ;\left(R^{2}=0.95\right)
\end{aligned}
$$

It is noted that the derived expressions should be used with caution taking into account the limited number of experimental data and the specific parameters examined in current research (i.e. aspect ratio $H / D=2$, one layer of steel fabric, the characteristics of the grout and the overlap length). Further investigation is required before adopting and using them for design purposes.

\subsection{Comparison to steel and fiber-reinforced polymer confinement models}

The proposed simplified confinement model for the estimation of the compressive strength (Eq. 12(a)) for steel-reinforced grout (SRG) jacketed cylindrical specimens subjected to the aforementioned limitations is compared to various confinement models found in literature. Both analysis- and design-oriented FRP confinement models as well as steel confinement models were utilized in current study ([24-25, 31-49], Table 5). The objective was to see how the experimental data referring to the maximum compressive strength are correlated with the analytical results from various well-established confinement models.

The normalized compressive strength, $f_{c c}{ }^{\prime} / f_{c o}{ }^{\prime}$, versus the normalized lateral stress due to jacketing, $\sigma_{l a t} / f_{c o}$, of the proposed model is plotted in Fig. 16 along with the curves that correspond to the confinement models of Table 5. The experimental data appear as well. It is noted that in case of the confinement models of Teng et al. [25] and Rousakis et al. [49] an average curve was derived for both the $12 \mathrm{X}$ and $3 \mathrm{X} 2$ types of fabric utilizing the mechanical properties of the tested fabrics as appear in Table 3. 
The first thing to be observed is the large dispersion of the estimated normalized compressive strength values resulting from the application of the various confinement models. The curve that corresponds to the proposed expression lies between the curves of the Richart et al. [31] and the Miyauchi et al. [35] models. Isolating the experimental data (up to a value of $\sigma_{l a t} / f_{c o}=0.11$ corresponding to the confinement ratio of the low density fabrics), it seems that the Mander et al. [33] and the Toutanji [39] models provide an upper and lower limit, respectively.

\section{Conclusions}

The potential of steel fiber reinforced jackets combined with inorganic matrix for increasing the axial compressive capacity of concrete through confinement was experimentally investigated. For this purpose, 34 unreinforced cylindrical specimens having two different concrete compressive strengths with a height to diameter ratio $H / D=2$ (i.e. $H=300 \mathrm{~mm}, D=150 \mathrm{~mm}$ ) were tested in uniaxial compression. A single layer of steel fabric was applied, combined with inorganic matrix, and the alternative jacketing schemes were defined based on the density, the type of the fabric (12X and 3X2) and the overlap length. Based on the experimental results obtained and the limitations imposed by the specific parameters examined herein, the following conclusions are drawn:

1) Steel-reinforced grout jackets increased substantially both compressive strength and deformation capacity. The low density SRG jackets (1 cord/cm, Fig. 2(e)) are more effective than the other alternative examined jacketing schemes indicating optimum use of the material. The $10 \mathrm{~mm}$ gap between steel cords allowed unhindered flow of the cementitious grout, thus the embedded fabric developed such a bond strength that in combination with the axial stiffness / strength of the fabric led to an efficient confining scheme. The calculated confinement ratios for the most efficient SRG jacketing scheme (i.e. $1 \mathrm{cord} / \mathrm{cm}$, overlap length $360 \mathrm{~mm}$ ) are equal to $\sigma_{\text {lat }} f_{c o}{ }^{\prime}=0.10$ and $\sigma_{\text {lat }} / f_{c o}{ }^{\prime}=0.11$ for the $12 \mathrm{X}$ and the $3 \mathrm{X} 2$ steel fabrics, respectively.

2) The overlap length equal to $360 \mathrm{~mm}$ provided adequate anchorage for the low density SRG jacketed cylindrical specimens allowing tensile fracture of the fabric to occur. In case of the medium and high density fabrics, this overlap length proved to be insufficient leading to debonding. The overlap length equal to $120 \mathrm{~mm}$ of the cylindrical specimens, which was selected based on the usual field practice recommendation for wrapping of $\mathrm{R} / \mathrm{C}$ members with composite fabrics, proved to be insufficient for the low and medium density fabrics, thus rendering the application of such an overlap length to the high density SRG jackets meaningless.

3) Debonding at termination of the steel fabric and tensile fracture of the steel cords of the fabric were the two observed failure modes. When the high density fabrics, the development of an interlocking mechanism between the steel cords and the cementitious matrix was prevented due to the very small distances between them that inhibited penetration of the cementitious grout between successive cords. Therefore, the bond developed between the high density fabric and the mortar was influenced greatly by the bond characteristics of the mortar and the surface roughness of the steel fabric. The high density fabrics failed due to debonding. In the case of the medium and low density fabrics the penetration of the mortar through the spacing of the steel cords enhanced the developed bond between the fabric and the matrix which in conjunction with 
the lower axial stiffness of the fabrics, rendered the overlap length a determinant parameter for the mode of failure occurring.

4) The effectiveness of the proposed jacketing scheme is a balance between the axial stiffness / strength of the fabric and the bond developed between the fabric and the mortar (which serves as the matrix of the composite system). That means that the stiffer the fabric the higher quality bonding is required to resist the higher tensile forces developed in the fabric due to the passive reaction to the confinement. Thus, the high density SRG jackets with high stiffness / strength, due to the difficulty of being penetrated by the cementitious material, will lead to debonding failure easily, thus rendering their application of less practical interest than that of the low or medium density SRG jackets.

5) A simple confinement model was derived for SRG jacketed cylinders considering the effect of the SRG jacket the same as that of the external reinforcement. Empirical factors were derived which relate the confined strength $f_{c c}{ }^{\prime}$ and ultimate strain $\varepsilon_{c c u}$ to their unconfined counterparts by a linear relation. The proposed expression for concrete confined strength was compared to well-established fiber-reinforced polymer and steel confinement models. It is noted that more experimental data are required before adopting any kind of expression for SRG confined cylinders. The derived expressions are imposed to limitations referring to aspect ratio of the specimens $(H / D=2)$, the number of steel fabric layers (one layer of fabric) as well as to the mechanical characteristics of the cementitious grout utilized.

6) Wrapping of concrete cylinders with unidirectional steel fabric bonded with cementitious binder resulted in a rather promising confinement technique. The response related to the level of axial strength and ductility attained was improved substantially with a single layer of steel fabric. The effect of the cementitious matrix on the redundancy of the jacketing scheme was determinant eliminating any kind of brittle failure modes. Further research should focus on the optimization of the technique regarding the balance between strength of the fabric (i.e. density) and properties of the grout. Moreover, the effect of multiple layers, the cross section shape, the interaction with steel reinforcement and cyclic loading are open issues that need be addressed.

\section{Acknowledgements}

The authors wish to thank the civil engineer Mrs S. Karathanou, Dr. V. Kouftidis and Mr. T. Koukouftopoulos, and for their assistance in the experimental program. The program was conducted in the Laboratory of Strength of Materials and Structures and funded by the Research Committee of Aristotle University of Thessaloniki within the framework of the program "Funding for new researchers". The materials were donated by SIKA Hellas and Interbeton.

\section{List of symbols}

$D \quad$ Diameter of cylindrical specimens

$D_{c} \quad$ Diameter of the steel cord

$f_{c c}{ }^{\prime} \quad$ Compressive strength of the confined concrete

$f_{c c}{ }^{\prime} \quad$ Ultimate compressive strength of the confined concrete $\left(80 \% f_{c c}{ }^{\prime}\right)$

$f_{c o}{ }^{\prime} \quad$ Compressive strength of the unconfined concrete

$f_{f u, s} \quad$ Failure stress of the steel-reinforced fabric 
$f_{g, u} \quad$ Rupture shear strength of the grout

$f_{s, d e b} \quad$ Transverse stress at debonding failure of the jacket layer

$f_{s, e f f} \quad$ Transverse effective stress

$f_{s, \text { rupt }}$ Transverse stress reached at rupture of the steel reinforced fabric

$H \quad$ Height of the specimen

$K \quad$ Axial stiffness

$K_{\text {eff }} \quad$ Effectiveness coefficient

$n \quad$ Number of cords per $\mathrm{cm}$

$s \quad$ Distance between successive cords

$s^{\prime}\left(=s-D_{c}\right)$ Clear spacing between the steel cords

$s_{g, u} \quad$ Slip value at shear failure of the grout

$t_{s} \quad$ Equivalent thickness per width of the steel fabric

Greek symbols

$\alpha, \beta \quad$ Empirical constants

$\varepsilon_{c o} \quad$ Strain at failure of the unconfined concrete

$\varepsilon_{c c} \quad$ Strain corresponding to the compressive strength of the confined concrete

$\varepsilon_{c c u} \quad$ Strain at failure of the confined concrete at $80 \% f_{c c}{ }^{\prime}$

$\kappa, \lambda \quad$ Empirical constants

$\rho_{S R G} \quad$ Volumetric ratio of the SRG jacket

$\sigma_{\text {lat }} \quad$ Lateral confining stress due to jacketing

\section{References}

1. Kurtz S, Balaguru P (2001) Comparison of inorganic and organic matrices for strengthening of RC Beams with carbon sheets. J. Struct Eng 127(1): 35-42.

2. Triantafillou TC, Papanicolaou CG, Zissimopoulos P, Laourdekis T (2006) Concrete confinement with textile-reinforced mortar jackets. ACI Struct J 103(1): 28-37.

3. Barton B, Wobbe E, Dharani LR, Silva P, Birman V, Nanni A, Alkhrdaji T, Thomas J, Tunis G (2005) Characterization of reinforced concrete beams strengthened by steel reinforced polymer and grout (SRP and SRG) composites. Mater Sci Eng: A 412:129-136.

4. Casadei P, Nanni, Alkhrdaji T, Thomas J (2005) Performance of double-T prestressed concrete beams strengthened with steel reinforced polymer. ACI Special Publication SP-230: 763-778.

5. Figeys W, Schueremans L, Brosens K, Van Gemert D (2005) Strengthening of concrete structures using steel wire reinforced polymer. ACI Special Publication SP-230: 743-762.

6. Katakalos K, Papakonstantinou CG (2009) Fatigue of reinforced concrete beams strengthened with steel-reinforced inorganic polymers. J Compos Construct 13(2):103-112.

7. Kim YJ, Fam A, Green MF (2010) Flexural strengthening of reinforced concrete beams with steel-reinforced polymer composites: analytical and computational investigations. J Reinf Plast Compos 29(14): 2141-2155.

8. Kim YJ, Fam A, Green MF (2010) Application of SRP composite sheets for retrofitting reinforced concrete beams: Cracking and tension stiffening. J Reinf Plast Compos 29(17): 2647-2662. 
9. Kim YJ, Fam A, Kong A, El-Hacha R (2005) Flexural strengthening of RC beams using steel reinforced polymer (SRP) composites. ACI Special Publication SP-230: 1647-1664.

10. Lopez A, Galati N, Alkhrdaji T, Nanni A (2007) Strengthening of a reinforced concrete bridge with externally bonded steel reinforced polymer (SRP). J Compos B: Eng 38(4): 429-436.

11. Pecce M, Ceroni F, Prota A, Manfredi G (2006) Response prediction of RC beams externally bonded with steel-reinforced polymers. J Compos Construct 10(3):195-203.

12. Prota A, K-Y Tan, Nanni A, Pecce M, Manfredi G (2006) Performance of shallow reinforced concrete beams with externally bonded steel-reinforced polymer. ACI Struct J 163(2): 163-170.

13. Mitolidis GJ, Salonikios TN, Kappos AJ (2012) Tests on RC beams strengthened at the span with externally bonded polymers reinforced with carbon or steel fibers. J Compos Construct 16(5): 551-562.

14. Manos GC, Katakalos K, Papakonstantinou CG (2011) Shear behavior of rectangular beams strengthened with either carbon or steel fiber reinforced polymers. Appl Mech Mater 82:571-576

15. Thermou GE, Pantazopoulou SJ (2007) Metallic fabric jackets: an innovative method for seismic retrofitting of substandard RC prismatic members. fib Struct Concr J 8(1): 35-46.

16. El-Hacha R, Mashrik MA (2012) Effect of SFRP confinement on circular and square concrete columns. Eng Struct 36(3): 379-393.

17. El-Hacha R, Abdelrahman K (2013) Slenderness effect of circular concrete specimens confined with SFRP sheets. J Compos B: Eng 44(1): 152-166.

18. De Lorenzis L, Tamužs V, Tepfers R, Valdmanis V, Vilks U (2004) Stability of CFRP confined columns. IMTCR 2004. Innovative Materials and Technologies for Construction and Restoration Conference, Lecce, June 6-9, 327-342.

19. Valdmanis V, De Lorenzis L, Rousakis T, Tepfers R (2007) Behavior and capacity of CFRP-confined concrete cylinders subjected to monotonic and cyclic axial compressive load. fib Struct Concr J 8(4).

20. Huang X, Birman V, Nanni A, Tunis G (2005) Properties and potential for application of steel reinforced polymer and steel reinforced grout composites. J Compos B: Eng 36(1): 73-82.

21. Eurocode 2 (2004) Design of concrete structures - Part 1-1: General rules and rules for buildings. EN 1992-1-1:2004, European Committee for Standardization (CEN), Brussels.

22. American Society for Testing and Materials (2008) "ASTM D3039 / D3039M - 08, Standard test method for tensile properties of polymer matrix composite materials, ASTM, West Conshohocken, PA, USA.

23. Mirmiran A, Shahawy M, Samaan M, El Echary H, Mastrapa JC, Pico O (1998) Effect of column parameters on FRP-confined concrete. ASCE J Compos Construct 2(4): 175-185. 
24. Spoelstra MR, Monti G (1999) FRP-confined concrete model. J Compos Constr 3(3): 143-150.

25. Teng JG, Jiang T, Lam L, Luo YZ (2009) Refinement of a design-oriented stress-strain model for FRP-confined concrete. ASCE J Compos Construct 13(4): 269-278.

26. Micelli F, Modarelli R (2013) Experimental and analytical study on properties affecting the behavior of FRP-confined concrete. J Compos B: Eng 45(1): 1420-1431.

27. Realfonzo R, Napoli A (2011) Concrete confined by FRP systems: confinement efficiency and design strength models. J Compos B: Eng 42(4): 736-755.

28. Tastani SP, Pantazopoulou SJ, Zdoumba D, Plakantaras V, Akritidis E (2006) Limitations of FRP jacketing in confining old-type reinforced concrete members in axial compression. J Compos Construct 10 (1):13-25.

29. Tastani SP, Pantazopoulou SJ (2008) Detailing procedures for seismic rehabilitation of reinforced concrete members with fiber reinforced polymers. Eng Struct 30 (2): 450-461.

30. fib Bulletin 14 (2001) Externally bonded FRP reinforcement for RC structures. Report by Task group 9.3, fédération internationale du béton (fib), Lausanne, Switzerland.

31. Richart FE, Brandtzaeg A, Brown RL (1928) A study of the failure of concrete under combined compressive stresses. Bulletin No. 185, Engineering Experimental Station, Univ. of Illinois, Urbana, Ill.

32. Newman K, Newman JB (1971) Failure theories and design criteria for plain concrete. Proc Int Civ Eng Mat Conf on Struct, Solid Mech. and Eng. Des. Wiley Interscience, New York, 936-995.

33. Mander JB, Priestley MJN, Park R (1988) Theoretical stress-strain model for confined concrete. J Struct Eng 114(8): 1804-1826.

34. Mirmiran A, Shahawy M (1997) Behavior of concrete columns confined by fiber composites. J. Struct. Eng., 123(5): 583-590.

35. Miyauchi K, Nishibayashi S, Inoue S (1997) Estimation of strengthening effects with carbon fiber sheet for concrete column. Proc. FRPRCs-3, Saporo, Japan 1: 217-224.

36. Karbhari VM, Gao Y (1997) Composite jacketed concrete under uniaxial compression-Verification of simple design equations. J. Mater. Civ. Eng., 9(4): 185-193.

37. Samaan M, Mirmiram A, Shahawy M (1998) Model of concrete confined by fiber composites. J Struct Eng 124(9): 1025-1031.

38. Saafi M, Toutanji HA, Li Z (1999) Behavior of concrete columns confined with fiber reinforced polymer tubes. ACI Mater J 96(4): 500-509.

39. Toutanji H. (1999) Stress-strain characteristics of concrete columns externally confined with advanced fiber composite sheets. ACI Mater J 96(3): 397-404.

40. Razvi S, Saatcioglu M (1999) Confinement model for high strength concrete. J. Struct. Eng., 125(3): 281-289. 
41. Lam L, Teng JG (2002) Strength models for fiber-reinforced plastic-confined concrete. J. Struct. Eng., 128(5):612-623.

42. Matthys S, Toutanji H, Audenaert K, Taerwe L (2005) Axial behavior of large-scale columns confined with fiber-reinforced polymer composites. ACI Struct. J., 102(2): 258-267.

43. Vintzileou E, Panagiotidou E (2008) An empirical model for predicting the mechanical properties of FRP-confined concrete. Construct Build Mater 22:841-854.

44. Youssef MN, Feng Q, Mosallam AS (2007) Stress-strain model for concrete confined by FRP composites. Composites, Part B, 38, 614-628.

45. ACI Committee 440 (2007). Report on fiber-reinforced polymer (FRP) reinforcement for concrete structures, ACI 440R-07, American Concrete Institute, Detroit.

46. Wu Y F, Wang LM (2009) A unified strength model for square and circular concrete columns confined by external jacket. J. Struct. Eng. 135(3): 253261.

47. Wu Y-F, Zhou Y-W (2010) Unified strength model based on hoek-brown failure criterion for circular and square concrete columns confined by FRP. J Compos Constr 14(2): 175-184.

48. Bo H. (2013) An improved criterion for sufficiently/insufficiently FRPconfined concrete derived from ultimate axial stress. Eng Struct 46: 431446.

49. Rousakis TC, Rakitzis TD, Karabinis AI (2012) Design-Oriented strength model for FRP-confined concrete members. J Compos Constr 16(6): 615625 . 


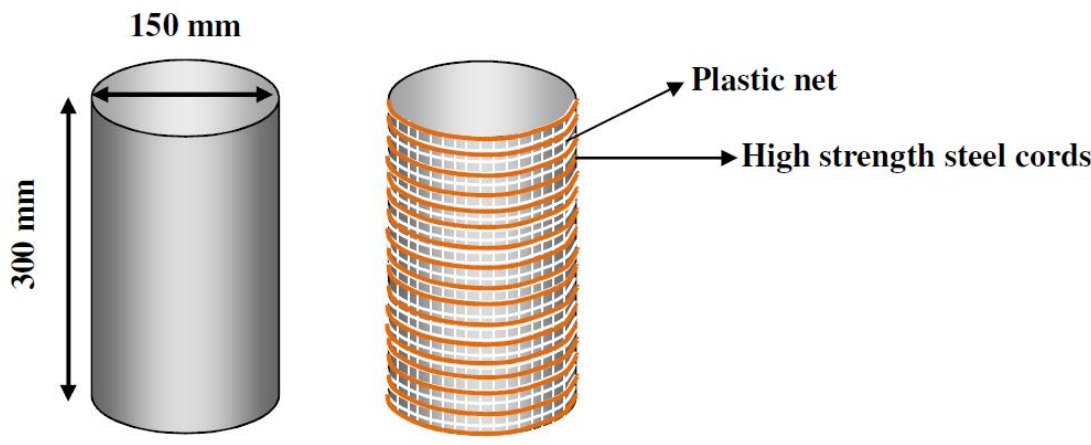

Figure 1: Concrete cylinder dimensions; wrapping with SRG jackets.
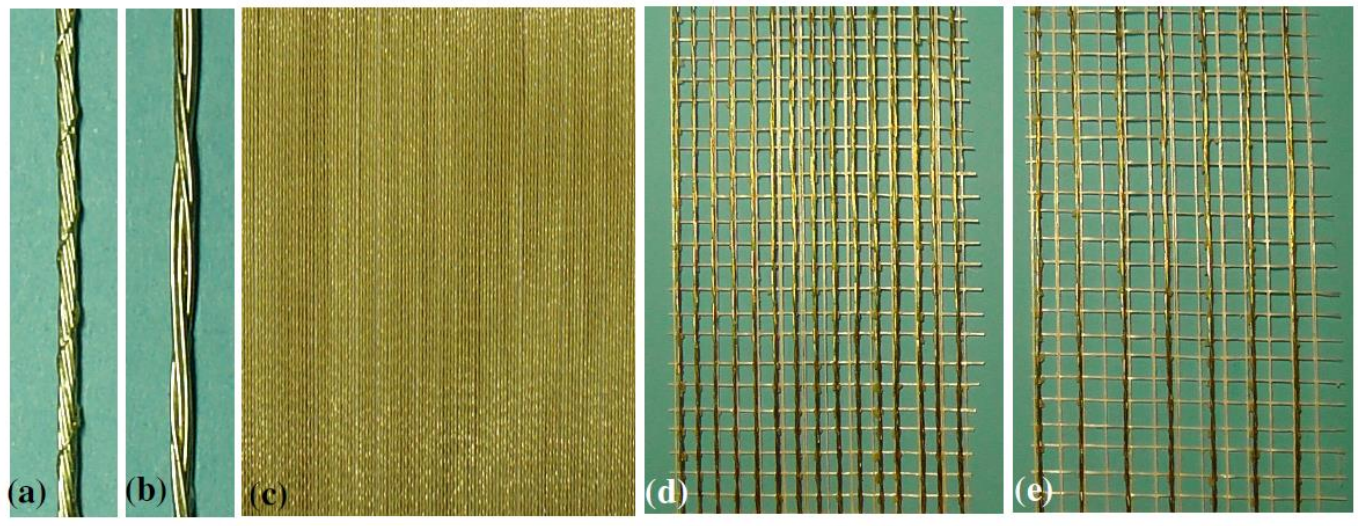

Figure 2: (a) and (b) High strength steel cord types; (c) High density; (d) Medium density fabric (2 cords/cm); (e) Low density fabric (1 cord/cm).

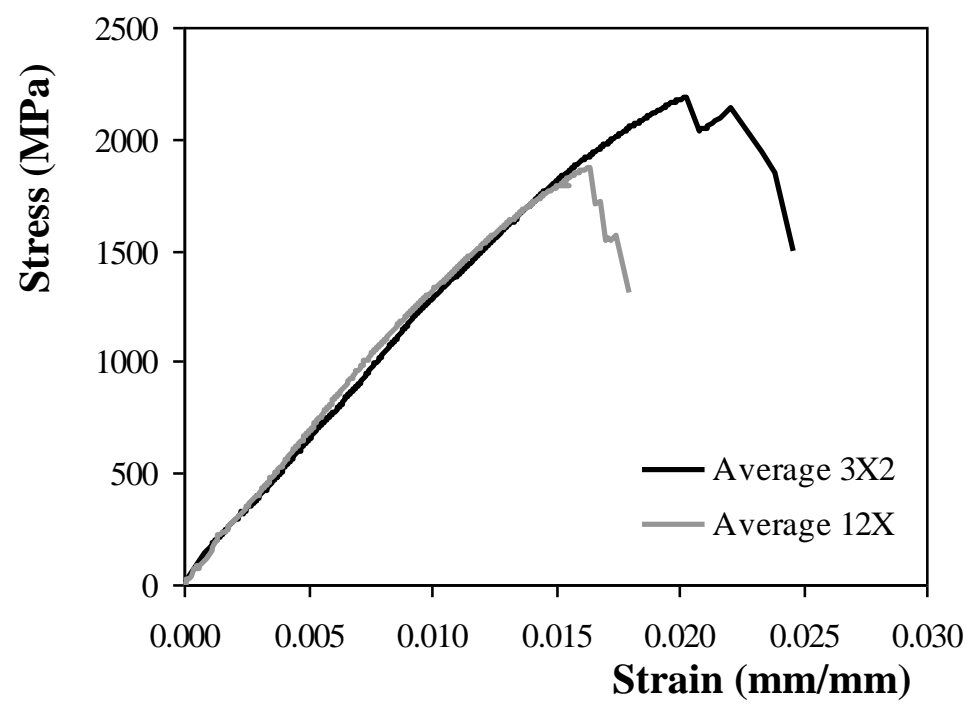

Figure 3: Tensile stress-strain diagrams for the steel reinforced fabrics. 


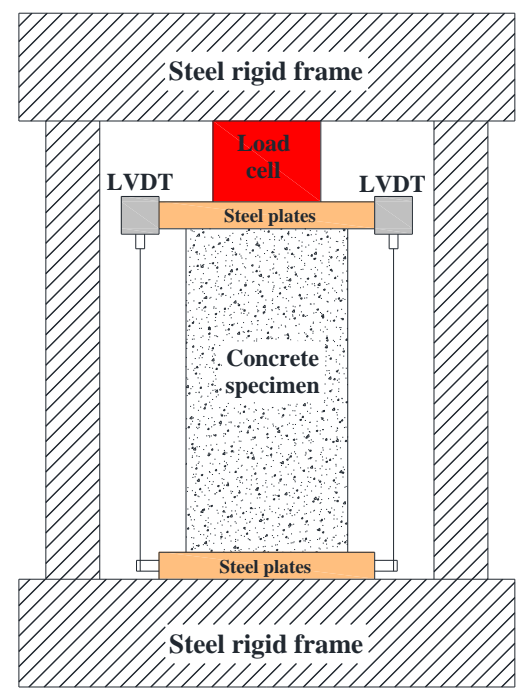

Figure 4: Test setup
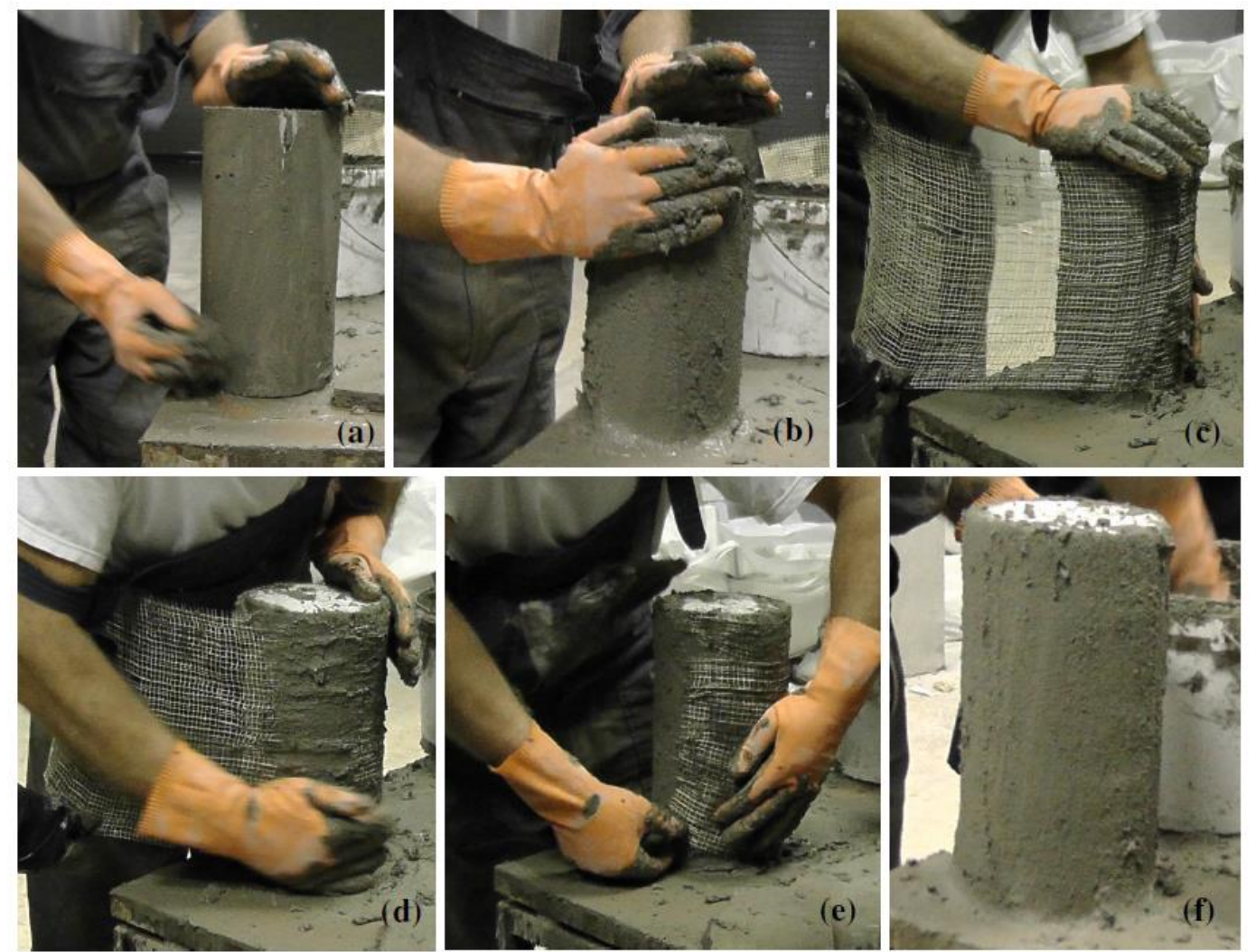

Figure 5: Steps of the method of application: (a) saturation of the specimen with water; (b) application of a thin layer of cementitious grout; (c), (d), (e) application of the steel-reinforced fabric; (f) specimen at final stage of retrofitting. 

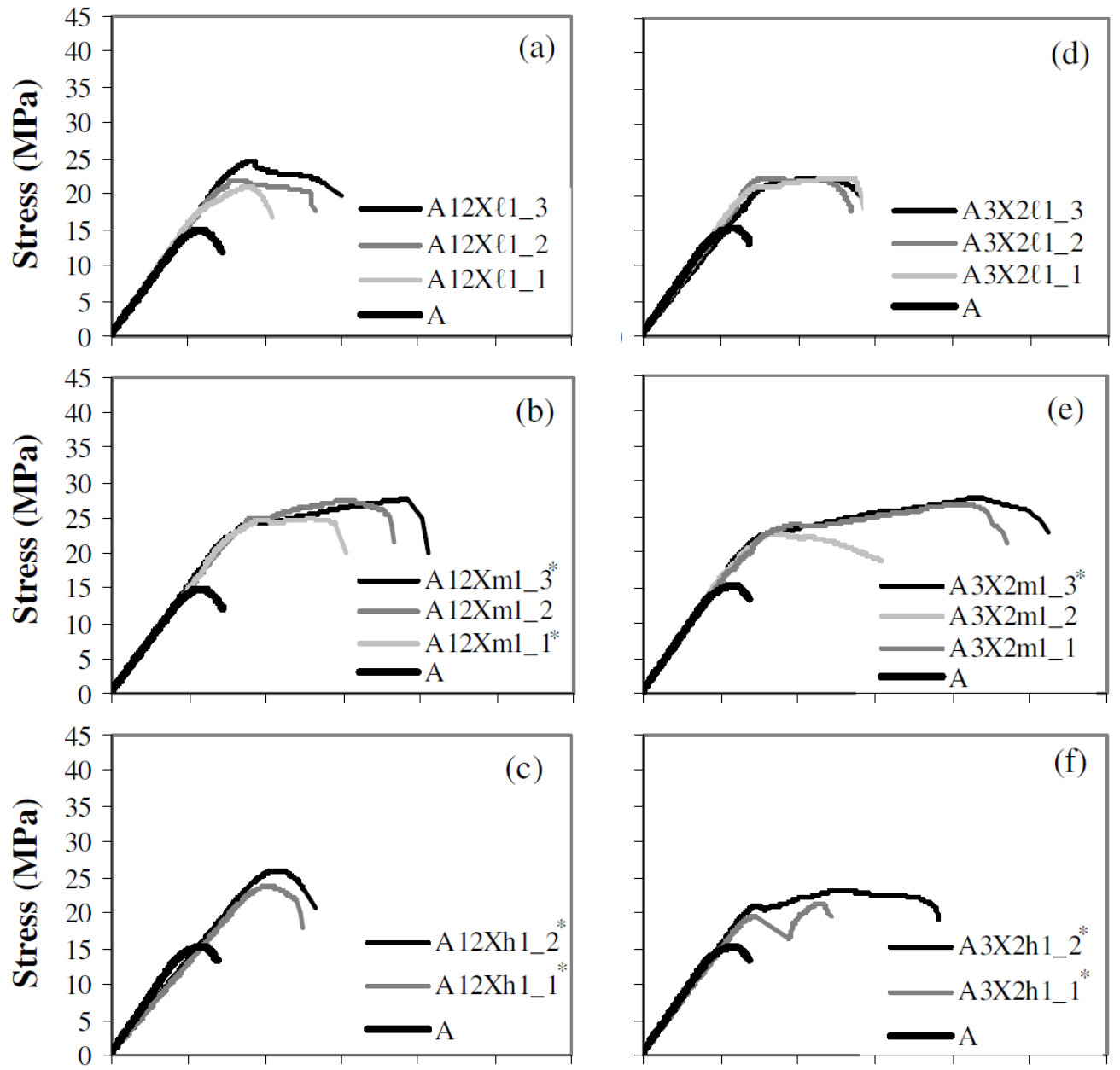

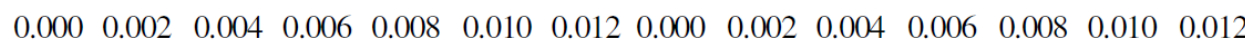

Strain $(\mathbf{m m} / \mathbf{m m})$

Strain $(\mathbf{m m} / \mathbf{m m})$

Figure 6: Stress - strain curves for specimens in Group A: (a), (b), (c) Specimens with 12X fabric of low, medium and high density, respectively; (d), (e), (f) Specimens with 3X2 fabric of low, medium and high density, respectively. The average curve of control specimens (A) also appears for comparison reasons ("The asterisk denotes those specimens that failed due debonding of the fabric).

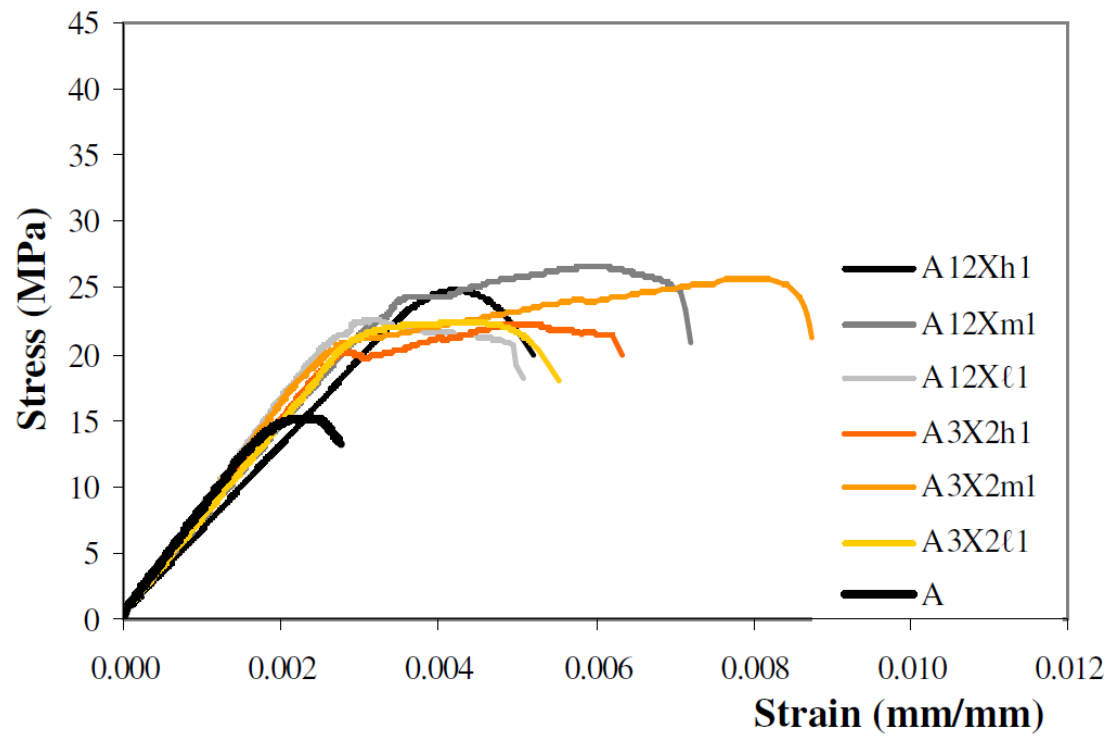

Figure 7: Comparison of the average stress - strain curves for all the types of SRG jackets in specimens of Group A. 

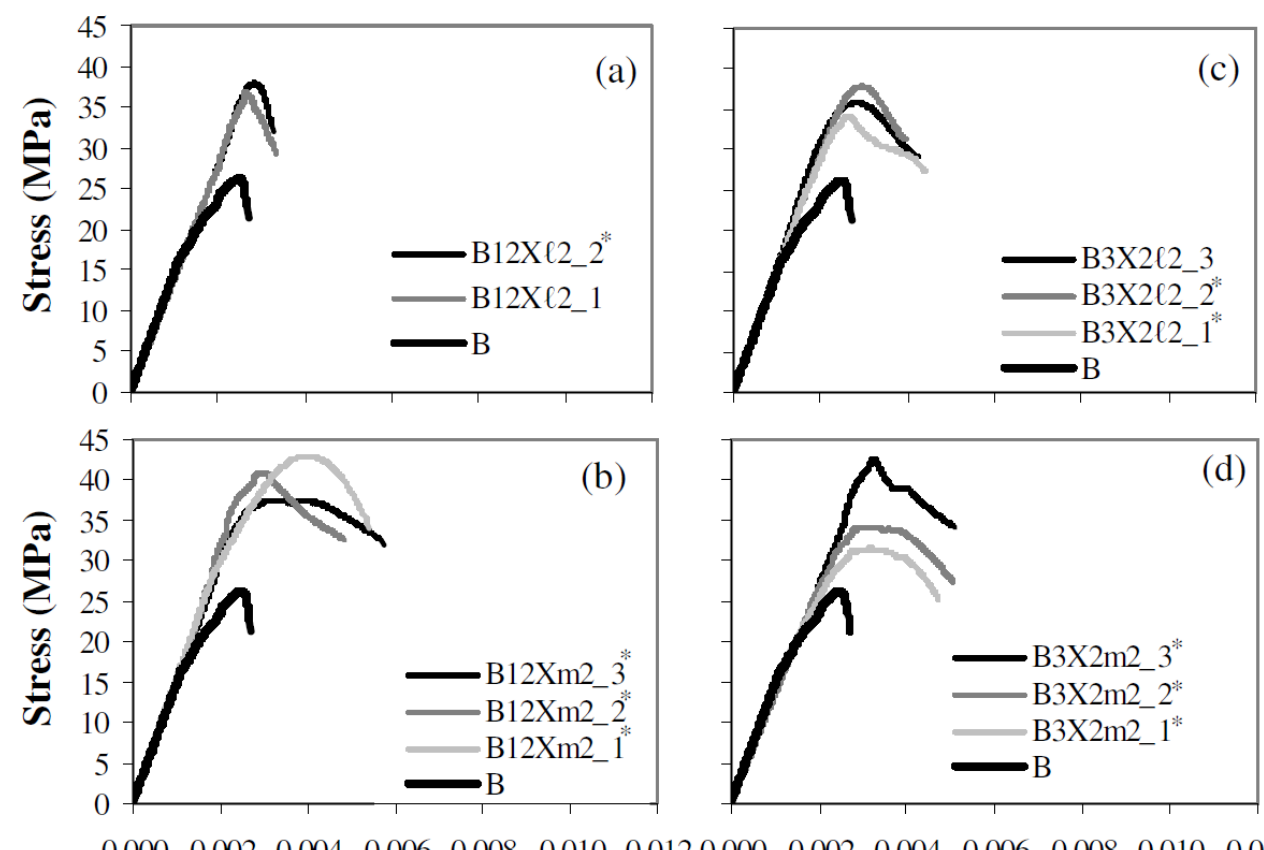

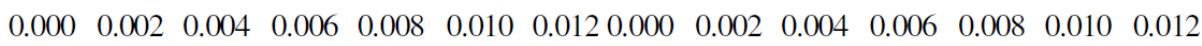

Strain $(\mathbf{m m} / \mathbf{m m})$

Strain $(\mathbf{m m} / \mathbf{m m})$

Figure 8: Stress - strain curves for specimens of Group B: (a), (b) Specimens with 12X fabric of low and medium density, respectively; (c), (d) Specimens with 3X2 fabric of low and medium, respectively. The average curve of control specimens (B) also appears for comparison reasons ( ${ }^{*}$ The asterisk denotes those specimens that failed due debonding of the fabric).

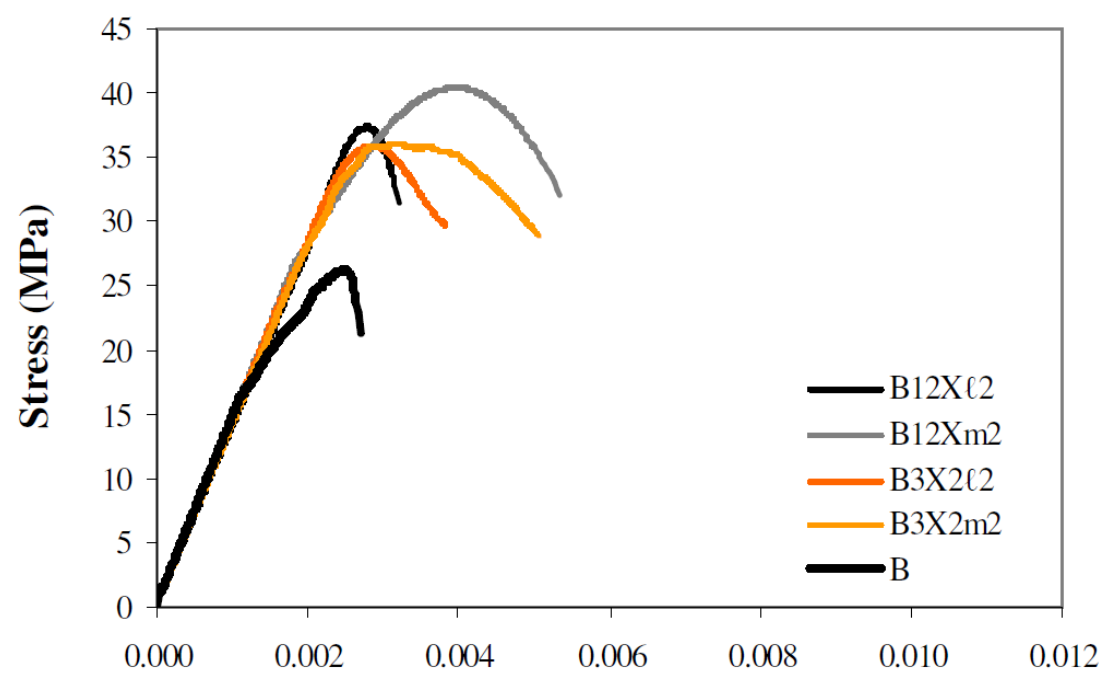

Figure 9: Comparison of the average stress - strain curves for all the types of SRG jackets in specimens of Group B. 

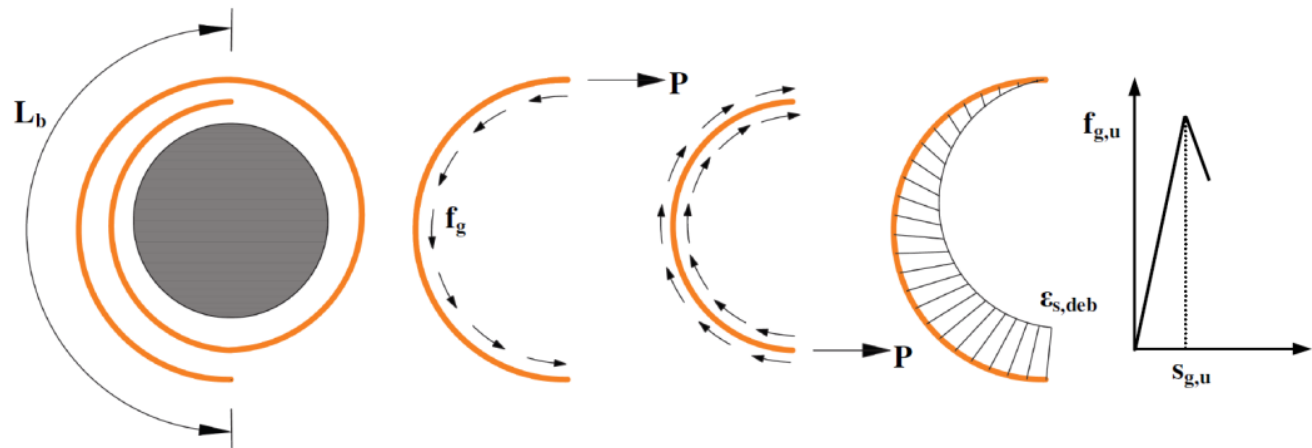

Figure 10: Grout stressed in shear over the lap length, $L_{p}$, of the steel reinforced fabric layer.

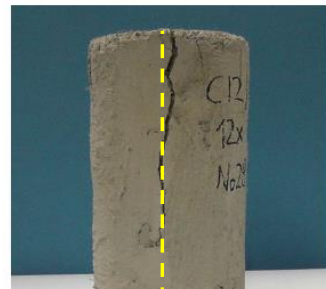

(a)

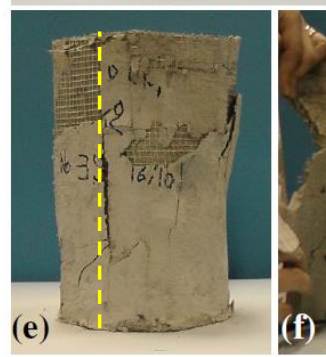

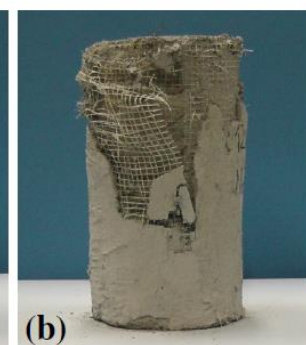
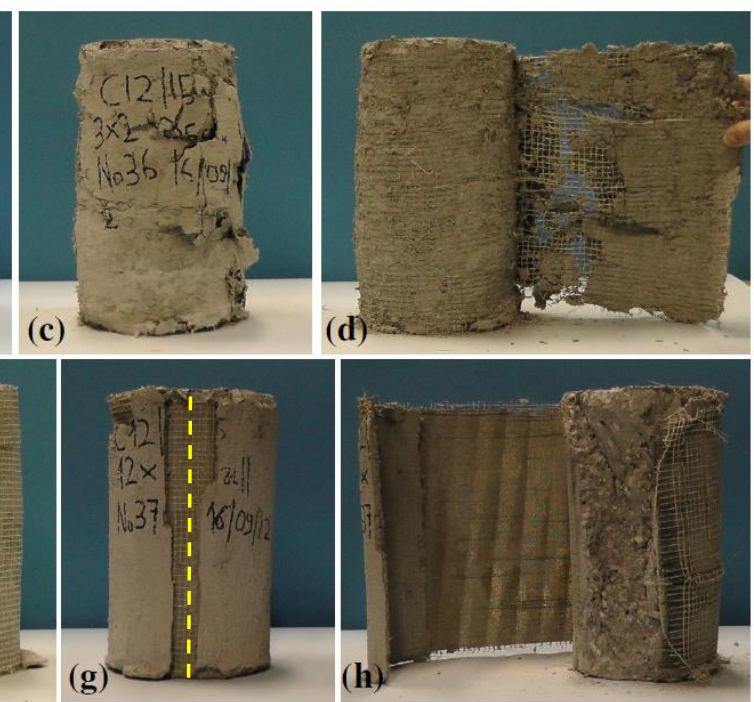

Figure 11: SRG jacketed cylinders at failure due to debonding at termination of the steel fabric: (a), (c), (e), (g) specimens at the end of the test; (b), (d), (f), (h) specimens after removal of loose mortar and concrete fragments.
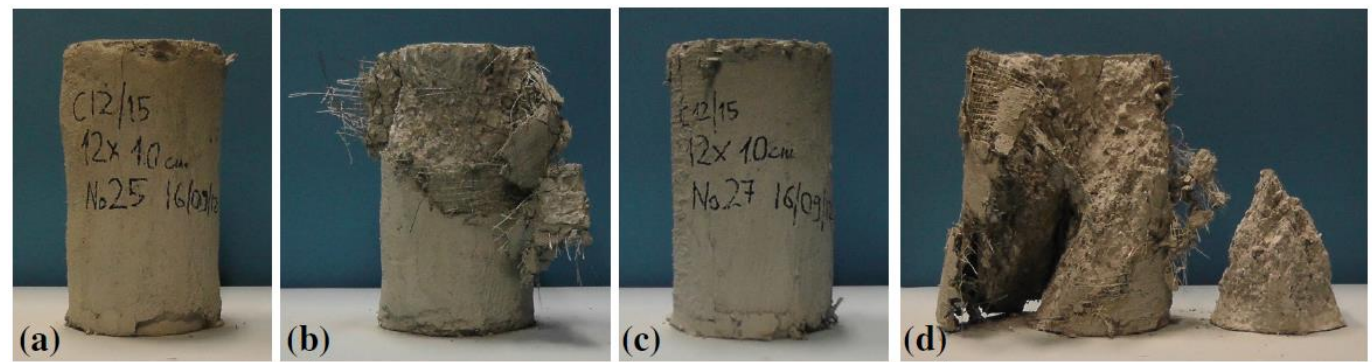

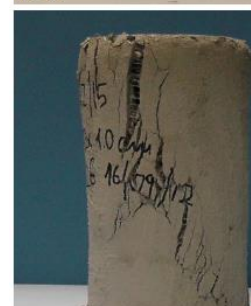

(e)

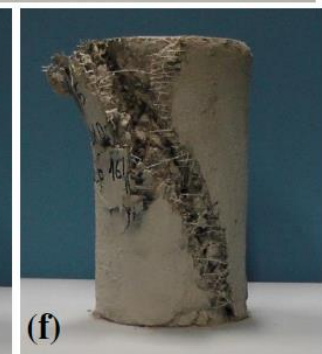

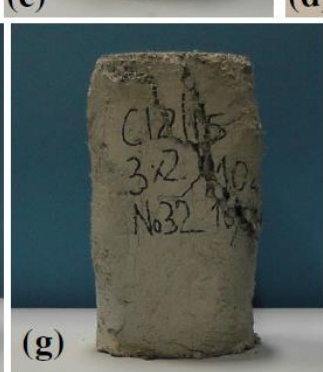

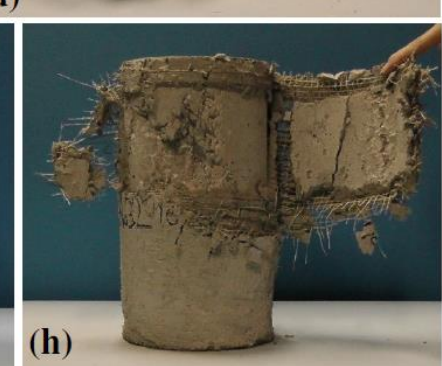

Figure 12: SRG jacketed cylinders at failure due to tensile fracture of the steel cords of the fabric: (a), (c), (e), (g) specimens at the end of the test; (b), (d), (f), (h) specimens after removal of loose mortar and concrete fragments. 

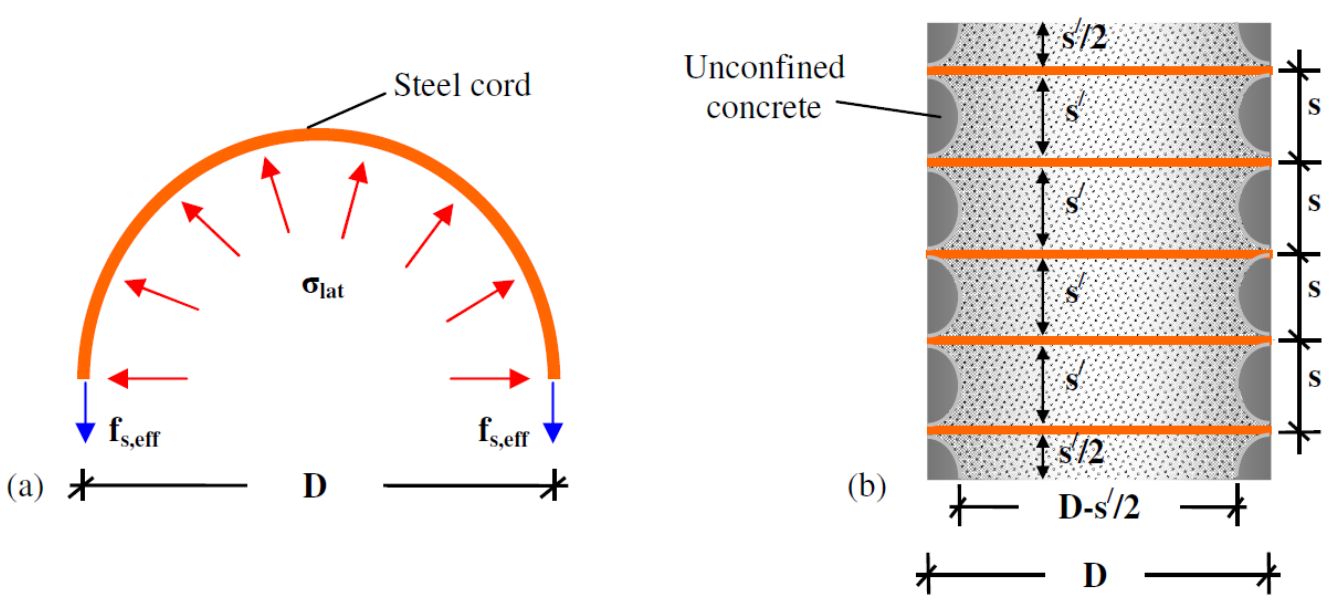

Figure 13: (a) Lateral confining pressure, $\sigma_{\text {lat }}$, exerted by the steel cord; (b) Influence of partial wrapping.

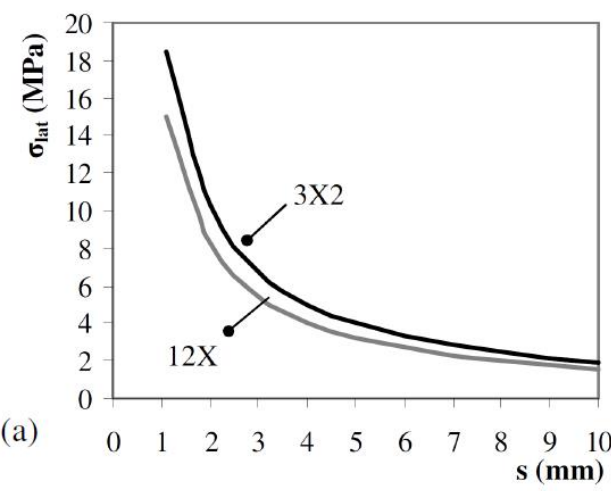

Equivalent thickness approach

$\square$ Steel stirrups approach

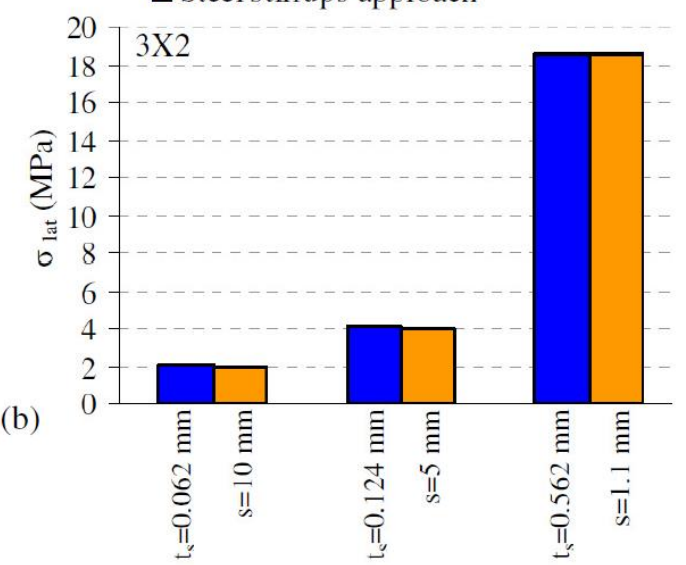

Figure 14: (a) Influence of the distance between cords on the lateral confining pressure exerted by the SRP jacket for cylindrical specimen of diameter $D=150 \mathrm{~mm}$ and for the $12 \mathrm{X}$ and $3 \mathrm{X} 2$ type of fabrics; (b) Comparison of the estimated lateral confining stress considering both the equivalent thickness approach (the steel fabric is treated as a composite fabric with equivalent thickness per unit width) and the steel stirrups approach (the steel cords are treated as steel stirrups placed at distance equal to the distance between cords) for the $3 \mathrm{X} 2$ steel fabric. 

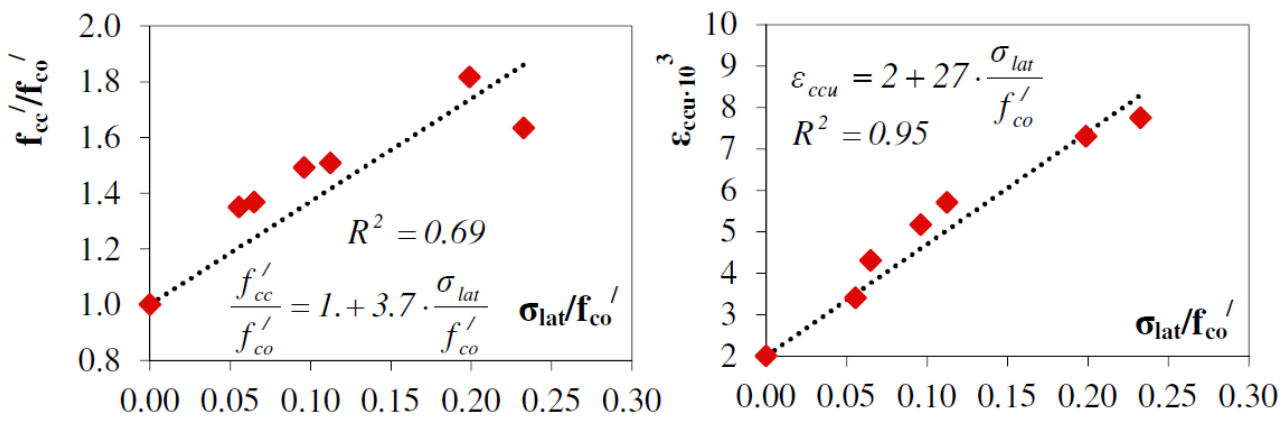

Figure 15: Normalized compressive strength, $f_{c c}{ }^{\prime} / f_{c o}{ }^{\prime}$, and ultimate compressive strain, $\varepsilon_{c c u}$, vs normalized lateral confinement strength, $\sigma_{l a t} / f_{c o}$, plots for the steel fabrics that failed due to rupture of the fabric.

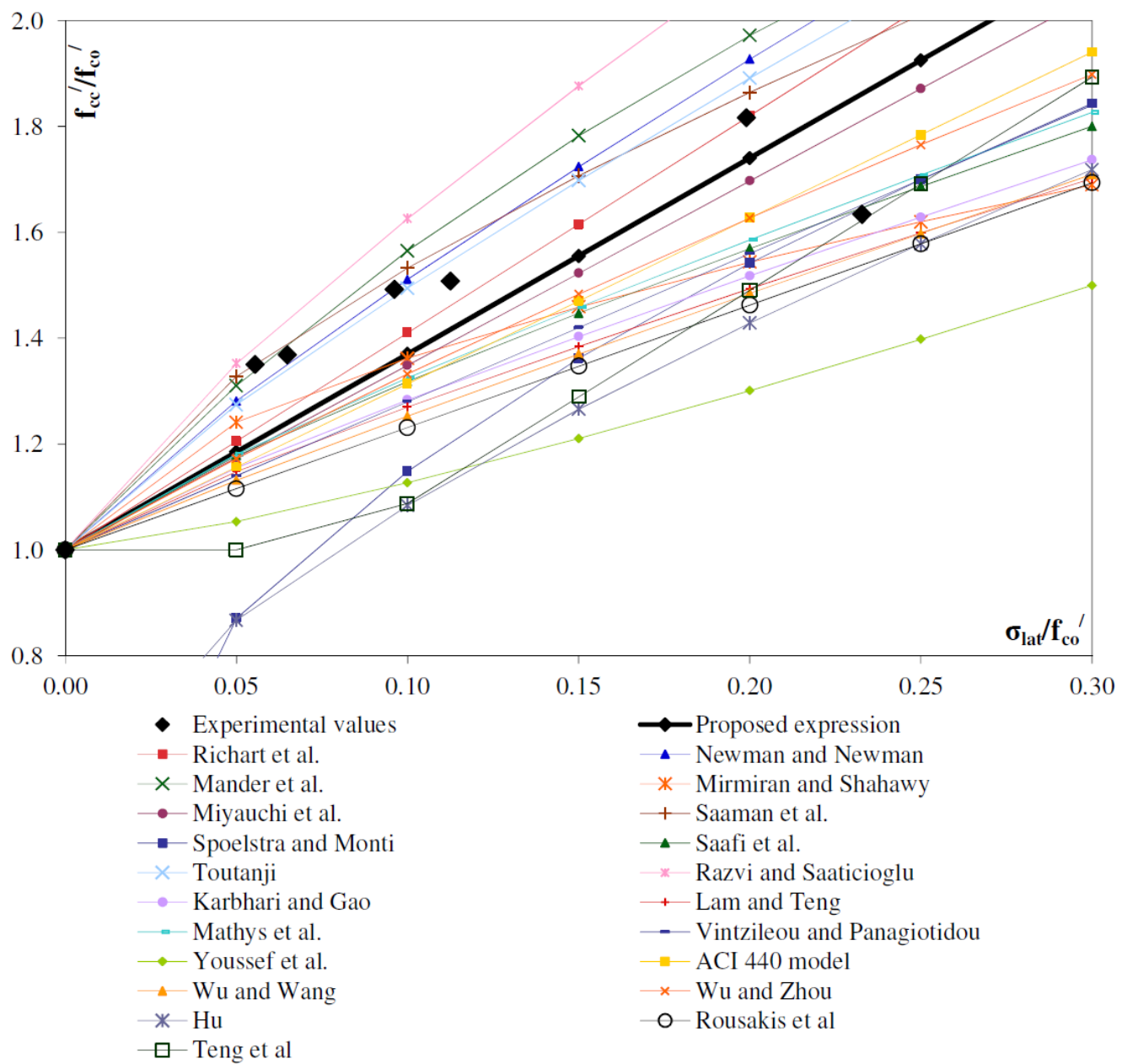

Figure 16: Comparison of the proposed expression for normalized compressive strength of steelreinforced grout jacketed cylinders to the concrete confinement models presented in Table 5. 
Table 1a: Test results of Group A.

\begin{tabular}{|c|c|c|c|c|c|c|c|c|c|c|c|c|c|c|c|}
\hline \multirow[t]{2}{*}{ No } & \multirow{2}{*}{$\begin{array}{l}\text { Specimen } \\
\text { notation }\end{array}$} & \multicolumn{3}{|c|}{$\begin{array}{c}\text { Compressive strength, } \\
f_{c c}^{\prime}(\mathrm{MPa})\end{array}$} & \multicolumn{3}{|c|}{$\begin{array}{l}\text { Ultimate compressive } \\
\text { strength, } f_{c c, u^{\prime}}(\mathrm{MPa})\end{array}$} & \multicolumn{3}{|c|}{ Strain, $\varepsilon_{c c}$} & \multicolumn{3}{|c|}{ Ultimate strain, $\varepsilon_{c c u}$} & \multirow[t]{2}{*}{$f_{c c}{ }^{\prime} l f_{c o}{ }^{\prime}$} & \multirow[t]{2}{*}{$\varepsilon_{c c u} / \varepsilon_{c}^{\#}$} \\
\hline & & value & mean & SD & value & mean & SD & value & mean & SD & value & mean & SD & & \\
\hline \multicolumn{16}{|c|}{ Group A } \\
\hline 1 & A_1 & 14.87 & \multirow{3}{*}{15.12} & \multirow{3}{*}{0.39} & 13.36 & \multirow{3}{*}{12.61} & \multirow{3}{*}{0.73} & 0.0024 & \multirow{3}{*}{000024} & \multirow{3}{*}{0.0001} & 0.0028 & \multirow{3}{*}{0.0033} & \multirow{3}{*}{0.0004} & \multirow{3}{*}{1.00} & \multirow{3}{*}{1.00} \\
\hline 2 & A_2 & 15.57 & & & 12.55 & & & 0.0023 & & & 0.0034 & & & & \\
\hline 3 & A_3 & 14.92 & & & 11.91 & & & 0.0024 & & & 0.0036 & & & & \\
\hline 4 & A3X2h1_1* & 21.29 & \multirow{2}{*}{22.26} & \multirow{2}{*}{1.38} & 19.46 & \multirow{2}{*}{19.36} & \multirow{2}{*}{0.14} & 0.0047 & \multirow{2}{*}{0.0050} & \multirow{2}{*}{0.0004} & 0.0049 & \multirow{2}{*}{0.0062} & \multirow{2}{*}{0.0020} & \multirow{2}{*}{1.47} & \multirow{2}{*}{3.12} \\
\hline 5 & A3X2h1_2* & 23.24 & & & 19.26 & & & 0.0052 & & & 0.0076 & & & & \\
\hline 6 & A3X2m1_1 & 26.73 & \multirow{3}{*}{25.66} & & 21.40 & & & 0.0083 & & & 0.0093 & & & & \\
\hline 7 & A3X2m1_2 & 22.67 & & 2.62 & 18.80 & 21.00 & 2.03 & 0.0033 & 0.0068 & 0.0030 & 0.0062 & 0.0087 & 0.0022 & 1.70 & 4.33 \\
\hline 8 & $\mathrm{~A} 3 \mathrm{X} 2 \mathrm{~m} 13^{*}$ & 27.58 & & & 22.80 & & & 0.0088 & & & 0.0105 & & & & \\
\hline 9 & A3X2l1_1 & 22.35 & & & 18.00 & & & 0.0055 & & & 0.0057 & & & & \\
\hline 10 & 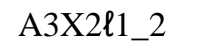 & 23.10 & 22.80 & 0.40 & 17.70 & 18.17 & 0.57 & 0.0044 & 0.0052 & 0.0007 & 0.0054 & 0.0057 & 0.0003 & 1.51 & 2.85 \\
\hline 11 & A3X2l1_3 & 22.94 & & & 18.80 & & & 0.0058 & & & 0.0060 & & & & \\
\hline 12 & A12Xh1_1* & 24.18 & 25.30 & 158 & 18.00 & 19.40 & 198 & 0.0041 & 0.0043 & 0.0002 & 0.0480 & 0.0050 & 0.0303 & 1.67 & 2.48 \\
\hline 13 & A12Xh1_2* & 26.41 & 25.30 & 1.58 & 20.80 & 19.40 & 1.98 & 0.0044 & 0.0043 & 0.0002 & 0.0051 & 0.0050 & 0.0303 & $1.0 /$ & 2.48 \\
\hline 14 & A12Xm1_1 ${ }^{*}$ & 24.84 & & & 20.00 & & & 0.0058 & & & 0.0061 & & & & \\
\hline 15 & A12Xm1_2 & 27.46 & 26.64 & 1.56 & 21.51 & 21.05 & 0.91 & 0.0062 & 0.0066 & 0.0010 & 0.0073 & 0.0072 & 0.0011 & 1.76 & 3.60 \\
\hline 16 & $\mathrm{~A} 12 \mathrm{Xm} 13^{*}$ & 27.63 & & & 21.63 & & & 0.0077 & & & 0.0082 & & & & \\
\hline 17 & A12Xl1_1 & 20.94 & & & 16.80 & & & 0.0037 & & & 0.0042 & & & & \\
\hline 18 & A12Xl1_2 & 21.95 & 22.55 & 1.99 & 17.70 & 18.10 & 1.54 & 0.0034 & 0.0036 & 0.0002 & 0.0053 & 0.0052 & 0.0009 & 1.49 & 2.58 \\
\hline 19 & A12X $11 \_3$ & 24.77 & & & 19.80 & & & 0.0037 & & & 0.0060 & & & & \\
\hline
\end{tabular}

"The asterisk denotes those specimens that failed due debonding of the fabric." A common value for $\varepsilon_{c o}$ equal to $2 \%$ is considered in order for the $\varepsilon_{c c u}$ values of specimens of series A to be compared. 
Table 1b: Test results of Group B.

\begin{tabular}{|c|c|c|c|c|c|c|c|c|c|c|c|c|c|c|c|}
\hline \multirow[t]{2}{*}{ No } & \multirow{2}{*}{$\begin{array}{l}\text { Specimen } \\
\text { notation }\end{array}$} & \multicolumn{3}{|c|}{$\begin{array}{c}\text { Compressive strength, } \\
f_{c c}{ }^{\prime}(\mathrm{MPa})\end{array}$} & \multicolumn{3}{|c|}{$\begin{array}{l}\text { Ultimate compressive } \\
\text { strength, } f_{c c, u}(\mathrm{MPa})\end{array}$} & \multicolumn{3}{|c|}{ Strain, $\varepsilon_{c c}$} & \multicolumn{3}{|c|}{ Ultimate strain, $\varepsilon_{c c u}$} & \multirow[t]{2}{*}{$f_{c c}^{\prime} / f_{c o}{ }^{\prime}$} & \multirow[t]{2}{*}{$\varepsilon_{c c u} / \varepsilon_{c}^{\#}$} \\
\hline & & value & mean & SD & value & mean & SD & value & mean & SD & value & mean & SD & & \\
\hline \multicolumn{16}{|c|}{ Group B } \\
\hline 1 & B_1 & 26.14 & \multirow{3}{*}{26.20} & \multirow{3}{*}{0.06} & 21.60 & \multirow{3}{*}{21.67} & & 0.0025 & \multirow{3}{*}{0.0025} & \multirow{3}{*}{0.0001} & 0.0031 & \multirow{3}{*}{0.0029} & \multirow{3}{*}{0.0002} & \multirow{3}{*}{1.00} & \multirow{3}{*}{1.00} \\
\hline 2 & B_2 & 26.25 & & & 21.40 & & 0.31 & 0.0025 & & & 0.0027 & & & & \\
\hline 3 & B_3 & 26.2 & & & 22.00 & & & 0.0024 & & & 0.0029 & & & & \\
\hline 4 & B3X2m2_1* & 31.47 & \multirow{3}{*}{36.07} & \multirow{3}{*}{5.79} & 25.20 & \multirow{3}{*}{28.88} & \multirow{3}{*}{4.63} & 0.0031 & \multirow{3}{*}{0.0032} & \multirow{3}{*}{0.0001} & 0.0047 & \multirow{3}{*}{0.0050} & \multirow{3}{*}{0.0002} & \multirow{3}{*}{1.38} & \multirow{3}{*}{2.48} \\
\hline 5 & B3X2m2_2* & 34.17 & & & 27.37 & & & 0.0031 & & & 0.0051 & & & & \\
\hline 6 & B3X2m2_3* & 42.57 & & & 34.08 & & & 0.0033 & & & 0.0051 & & & & \\
\hline 7 & B3X2€2_1* & 34.08 & \multirow{3}{*}{35.93} & \multirow{3}{*}{1.89} & 27.29 & \multirow{3}{*}{29.04} & \multirow{3}{*}{2.03} & 0.0027 & & & 0.0044 & & & & \\
\hline 8 & $\mathrm{~B} 3 \mathrm{X} 2 \ell 2 \_2^{*}$ & 37.86 & & & 31.27 & & & 0.0031 & 0.0029 & 0.0002 & 0.0040 & 0.0042 & 0.0002 & 1.37 & 2.12 \\
\hline 9 & B $3 \times 2 \ell 2 \_3$ & 35.84 & & & 28.55 & & & 0.0028 & & & 0.0043 & & & & \\
\hline 10 & B12Xm2_1* & 42.99 & & & 34.15 & & & 0.0041 & & & 0.0054 & & & & \\
\hline 11 & B12Xm2_2* & 40.83 & 40.42 & 2.80 & 32.64 & 32.85 & 1.20 & 0.0030 & 0.0038 & 0.0007 & 0.0048 & 0.0053 & 0.0005 & 1.54 & 2.67 \\
\hline 12 & B12Xm2_3* & 37.43 & & & 31.77 & & & 0.0042 & & & 0.0058 & & & & \\
\hline 13 & B12X€2_1 & 36.78 & & & 29.42 & & & 0.0026 & & & 0.0034 & & & & \\
\hline 14 & $\mathrm{~B} 12 \mathrm{X} \ell 2 \_2^{*}$ & 37.90 & 36.21 & 2.04 & 31.99 & 30.71 & 1.82 & 0.0029 & 0.0028 & 0.0002 & 0.0033 & 0.0034 & 0.0001 & 1.38 & 1.68 \\
\hline 15 & B12X८2_3 & 33.95 & & & N/A & & & N/A & & & N/A & & & & \\
\hline
\end{tabular}

"The asterisk denotes those specimens that failed due debonding of the fabric." A common value for $\varepsilon_{c o}$ equal to $2 \%$ is considered in order for the $\varepsilon_{c c u}$ values of specimens of series B to be compared. 
Table 2: Geometrical and mechanical properties of single cord as provided by the manufacturer.

\begin{tabular}{ccccc}
\hline $\begin{array}{c}\text { Fabric } \\
\text { type }\end{array}$ & $\begin{array}{c}\text { Filament } \\
\text { diameters }(\mathrm{mm})\end{array}$ & $\begin{array}{c}\text { Cord diameter } \\
(\mathrm{mm})\end{array}$ & $\begin{array}{c}\text { Tensile strength } \\
f_{f u, s}, \mathrm{MPa}\end{array}$ & $\begin{array}{c}\text { Strain to failure } \\
\varepsilon_{f u, s},(\mathrm{~mm} / \mathrm{mm})\end{array}$ \\
\hline $12 \mathrm{X}$ & $3 \times 0.22,9 \times 0.20$ & 0.889 & 2013.8 & 0.019 \\
$3 \mathrm{X} 2$ & 0.35 & 0.889 & 2479.4 & 0.021 \\
\hline
\end{tabular}

Table 3: Mechanical properties of single cord as measured in the tests conducted.

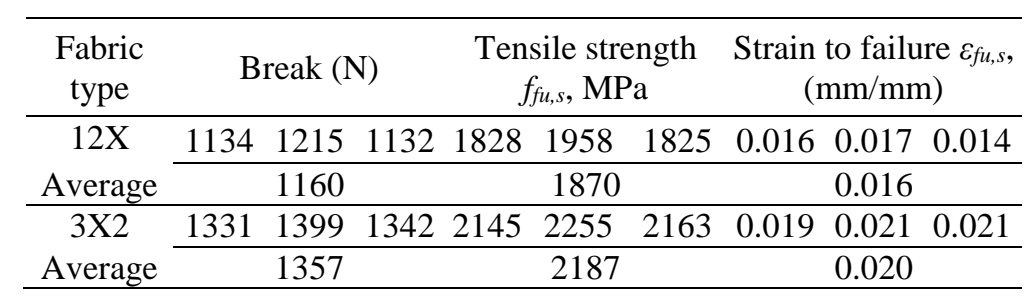

Table 4: Equivalent thickness, $t_{s}$, tensile strength, $f_{f u, s}$, and axial stiffness, $K_{f, s}$, of steel fabrics with varying density.

Fabric type 3X2-high 3X2-medium 3X2-low 12X-high 12X-medium 12X-low

\begin{tabular}{ccccccc}
\hline$t_{s}(\mathrm{~mm})$ & 0.562 & 0.124 & 0.062 & 0.562 & 0.124 & 0.062 \\
$f_{f u, s}(\mathrm{MPa})$ & 2187 & 2187 & 2187 & 1870 & 1870 & 1870 \\
$K_{f, s}(\mathrm{~N} / \mathrm{mm})$ & 73068.61 & 16138.6 & 8069.3 & 73068.61 & 16138.6 & 8069.3 \\
\hline
\end{tabular}


Table 5: Confinement models for concrete cylinders.

\begin{tabular}{|c|c|}
\hline Model & Theoretical $\mathrm{f}_{\mathrm{cc}}{ }^{\prime} / \mathrm{f}_{\mathrm{co}}$ \\
\hline Richart et al. (1928) & $f_{c c}^{\prime} / f_{c o}^{\prime}=1+4.1 \cdot \sigma_{\text {lat }} / f_{c o}^{\prime}$ \\
\hline $\begin{array}{l}\text { Newman and Newman } \\
\text { (1971) }\end{array}$ & $f_{c c}^{\prime} / f_{c o}^{\prime}=1+3.7 \cdot\left(\sigma_{l a t} / f_{c o}^{\prime}\right)^{0.86}$ \\
\hline Mander et al. (1988) & $f_{c c}^{\prime} / f_{c o}^{\prime}=2.254 \sqrt{1+7.94 \cdot \sigma_{\text {lat }} / f_{c o}^{\prime}}-2 \cdot \sigma_{\text {lat }} / f_{c o}^{\prime}-1.254$ \\
\hline $\begin{array}{l}\text { Mirmiran and Shahawy } \\
\text { (1997) }\end{array}$ & $f_{c c}^{\prime} / f_{c o}^{\prime}=1+4.269 \cdot \sigma_{l a t}^{0.587} / f_{c o}^{\prime}$ \\
\hline Miyauchi et al. (1997) & $f_{c c}^{\prime} / f_{c o}^{\prime}=1+3.485 \cdot \sigma_{l a t} / f_{c o}^{\prime}$ \\
\hline Karbhari and Gao (1997) & $f_{c c}^{\prime} / f_{c o}^{\prime}=1+2.1 \cdot\left(\sigma_{\text {lat }} / f_{c o}^{\prime}\right)^{0.87}$ \\
\hline Saaman et al. (1998) & $f_{c c}^{\prime} / f_{c o}^{\prime}=1+6.0 \cdot \sigma_{l a t}^{0.7} / f_{c o}^{\prime}$ \\
\hline Spoelstra and Monti (1999) & $f_{c c}^{\prime} / f_{c o}^{\prime}=0.2+3.0 \cdot\left(\sigma_{\text {lat }} / f_{c o}^{\prime}\right)^{0.5}$ \\
\hline Saafi et al. (1999) & $f_{c c}^{\prime} / f_{c o}^{\prime}=1+2.2 \cdot\left(\sigma_{l a t} / f_{c o}^{\prime}\right)^{0.84}$ \\
\hline Toutanji (1999) & $f_{c c}^{\prime} / f_{c o}^{\prime}=1+3.5 \cdot\left(\sigma_{\text {lat }} / f_{c o}^{\prime}\right)^{0.85}$ \\
\hline $\begin{array}{l}\text { Razvi and Saatcioglu } \\
\text { (1999) }\end{array}$ & $f_{c c}^{\prime} / f_{c o}^{\prime}=1+6.7 \cdot \sigma_{l a t}^{0.83} / f_{c o}^{\prime}$ \\
\hline Lam and Teng (2002) & $f_{c c}^{\prime} / f_{c o}^{\prime}=1+2.0 \cdot\left(\sigma_{\text {lat }} / f_{c o}^{\prime}\right)^{0.87}$ \\
\hline Matthys et al. (2005) & $f_{c c}^{\prime} / f_{c o}^{\prime}=1+2.3 \cdot\left(\sigma_{\text {lat }} / f_{c o}^{\prime}\right)^{0.85}$ \\
\hline $\begin{array}{l}\text { Vintzileou and } \\
\text { Panagiotidou (2007) }\end{array}$ & $f_{c c}^{\prime} / f_{c o}^{\prime}=1+2.8 \cdot \sigma_{l a t} / f_{c o}^{\prime}$ \\
\hline Youssef et al. (2007) & $f_{c c}^{\prime} / f_{c o}^{\prime}=1+2.25 \cdot\left(\sigma_{\text {lat }} / f_{c o}^{\prime}\right)^{5 / 4}$ \\
\hline ACI 440 Model (2008) & $f_{c c}^{\prime} / f_{c o}^{\prime}=1+\psi_{f} \cdot 3.3 \cdot \kappa_{a} \sigma_{\text {lat }} / f_{c o}^{\prime} ; \psi_{f}=0.95 ; \kappa_{a}=1.0$ \\
\hline Teng et al. (2009) & $\begin{array}{l}f_{c c}^{\prime} / f_{c o}^{\prime}=1+3.5 \cdot\left(\rho_{K}-0.01\right) \rho_{\varepsilon} ; \text { if } \rho_{K} \geq 0.01 \\
f_{c c}^{\prime} / f_{c o}^{\prime}=1 ; \text { if } \rho_{K}<0.01\end{array}$ \\
\hline & $\rho_{K}=2 E_{f} t_{f} /\left[\left(f_{c o}^{\prime} / \varepsilon_{c o}\right) D\right] ; \rho_{\varepsilon}=\varepsilon_{h, \text { rup }} / \varepsilon_{c o}$ \\
\hline Wu and Wang (2009) & $f_{c c}^{\prime} / f_{c o}^{\prime}=1+2.2 \cdot\left(\sigma_{\text {lat }} / f_{c o}^{\prime}\right)^{0.94}$ \\
\hline Wu and Zhou (2010) & $f_{c c}^{\prime} / f_{c o}^{\prime}=\sigma_{l a t} / f_{c o}^{\prime}+\sqrt{\left(16.7 / f_{c o}^{\prime 0.42}-f_{c o}^{\prime 0.42} / 16.7\right) \sigma_{l a t} / f_{c o}^{\prime}+1}$ \\
\hline Hu (2012) & $f_{c c}^{\prime} / f_{c o}^{\prime}=0.5+2.73 \cdot\left(\sigma_{l a t} / f_{c o}^{\prime}\right)^{0.67}$ \\
\hline Rousakis et al. (2012) & $\begin{array}{l}f_{c c}^{\prime} / f_{c o}^{\prime}=1+\left(\rho_{f} E_{f} / f_{c o}^{\prime}\right)\left(-0.336 E_{f} 10^{-6} / E_{f \mu}+0.0223\right) ; \\
E_{f \mu}=10 \mathrm{MPa}\end{array}$ \\
\hline
\end{tabular}

